CUADERNOS DE ESTUDIOS GALLEGOS, LIX Núm. 125 (enero-diciembre 2012), págs. 157-191

ISSN: 0210-847 X

DOI: $10.3989 /$ ceg.2012.125.07

\title{
LAS NUEVAS CASAS DE LA INQUISICIÓN EN SANTIAGO DE COMPOSTELA: DEL PALACIO DE MONTERREY A LA SEDE DE PORTA DA MÁMOA
}

\author{
Paula Pita Galán
}

Universidade de Santiago de Compostela 


\title{
LAS NUEVAS CASAS DE LA INQUISICIÓN EN SANTIAGO DE COMPOSTELA: DEL PALACIO DE MONTERREY A LA SEDE DE PORTA DA MÁMOA
}

\section{RESUMEN}

En 1726 el Tribunal de la Inquisición se propuso remodelar sus instalaciones en el Palacio de Monterrey, en Santiago de Compostela. Dicha intervención, que debía realizarse según un proyecto de Fernando de Casas, determinó el traslado del Santo Oficio a un nuevo inmueble: la Casa Grande del Hórreo o de Calo, frente a la Porta da Mámoa. A partir de documentación inédita y del estudio de la colección de planos de la Inquisición que conserva el Archivo Histórico Universitario de Santiago, analizaremos las circunstancias que motivaron el cambio de sede, y reconstruiremos la Casa de Calo según los testimonios de quienes la conocieron antes de que una profunda remoción dirigida por fray Francisco Velasco, maestro de obras de San Martín Pinario, la transformase en un palacio de la Inquisición.

PALABRAS ClAVE: Inquisición, Santiago de Compostela, arquitectura, barroco, Fernando de Casas y Novoa, fray Francisco Velasco

\section{AS NOVAS CASAS DA INQUISICIÓN EN SANTIAGO DE COMPOSTELA: DO PAZO DE MONTERREI Á SÉ DE PORTA DA MÁMOA}

\section{RESUMO}

En 1726 o Tribunal da Inquisición propúxose remodelar a súas instalacións no Pazo de Monterrey, en Santiago de Compostela. Dita intervención, que debíase realizar seguindo un proxecto de Fernando de Casas, determinou o traslado do Santo Oficio a un novo inmoble: a Casa Grande do Hórreo ou de Calo, frente a Porta da Mámoa. A partir de documentación inédita, e do estudio da colección de planos da Inquisición que conserva o Arquivo Histórico Universitario de Santiago, analizaremos as circunstancias que motivaron o cambio de sede, e reconstruiremos a Casa de Calo segundo as testemuñas dos que a coñeceron antes de que unha profonda reforma dirixida por frei Francisco Velasco, maestro de obras de San Martiño Pinario, a transformara nun pazo da Inquisición.

PALABRAS ClAVE: Inquisición, Santiago de Compostela, arquitectura, barroco, Fernando de Casas y Novoa, frei Francisco Velasco

\section{THE NEW HOUSES OF THE INQUISITION IN SANTIAGO DE COMPOSTELA: FROM THE PALACE OF MONTERREY TO THE NEW HOST OF PORTA DA MÁMOA}

\begin{abstract}
In 1726 the Inquisition decided to rebuild its building: the Palace of Monterrey, in Santiago de Compostela. This intervention should have been made according to a project of Fernando de Casas but caused the moving of the Santo Oficio to a new building known as Casa Grande del Horreo or de Calo, in front of Porta da Mámoa. Thanks to unknown documents and the collection of plates of the Inquisition conserved at Archivo Histórico Universitario de Santiago, we will analized the circumstances that caused the change of building as well as propose an hypothetical reconstruction of the Casa de Calo from the testimonies of those who knew it before of the deep removal, directed by the master mason of San Martín Pinario fray Francisco Velasco that transform it into a Palace of the Inquisition.
\end{abstract}

KEY WORDS: Inquisition, Santiago de Compostela, architecture, Baroque, Fernando de Casas y Novoa, fray Francisco Velasco 
Recibido/Received: 30/04/2012

Aceptado/Accepted: 14/08/2012

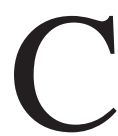

uando en 1574 la Inquisición se instaló en Compostela se le cedió como sede el antiguo palacio de los Condes de Monterrey, situado en el frente norte de la plazuela de San Miguel, y lindando con el cierre oriental de la huerta del monasterio benedictino de San Martín Pinario ${ }^{1}$. Desde un primer momento, la convivencia entre ambas instituciones no fue fácil y los problemas no finalizaron hasta que, para resolver uno de sus conflictos, los regulares se decidieron a buscar una nueva ubicación para el Tribunal ${ }^{2}$. En 1726, los ministros del Santo Oficio expusieron su voluntad de ampliar las dependencias de su sede y remodelar el edificio, siguiendo para ello un proyecto de Fernando de Casas y Novoa. Conociendo la voluntad de los inquisidores, el 17 de abril de ese mismo año los benedictinos acordaron llamar al maestro de obras de Samos, fray Juan Vázquez, para que reconociese el impacto de la obra sobre la propiedad mona$\mathrm{cal}^{3}$. El peritaje descubrió que la reforma implicaba la usurpación de una porción

\footnotetext{
${ }^{1}$ Sobre la inquisición gallega véase Jaime ConTreras, El Santo Oficio de la Inquisición de Galicia 1560-1700. Poder, sociedad y cultura, Akal, Madrid, 1982.

${ }^{2}$ Con los monjes de Pinario uno de los pleitos más sonados se produjo en 1607, cuando el Tribunal decidió erigir un edificio para las nuevas cárceles sobre la muralla de la huerta de San Martín, con un corredor descubierto y ventanas hacia el privado de los monjes. La obra se inició sin conocimiento de los regulares quienes al ver asomar la edificación sobre su muralla la denunciaron ante el Consejo de la Suprema, árbitro habitual en los enfrentamientos entre ambas instituciones. Bernardo Barreiro de Vázquez Varela, "Las casas primitivas del Santo Oficio en Santiago" Galicia diplomática, Tomo I, no 35 (1883), págs. 249-253 y Jaime ConTreras, El Santo Oficio..., pág. 329.

${ }^{3}$ En el acta de Consejo se informa acerca de la solicitud del Consejo de la Suprema "de un pedazo de nuestra huerta, que necesitaba para la fábrica que intentaba hacer el Santo Tribunal de esta ciudad, y que se llamase para el reconocimiento de sitio que se pedía al maestro de obras de Samos... para que con asistencia de los Padres maestros... reconociese lo que se pedía... y informase al $P$. Abad para que pudiese responder a los Señores de la Suprema". Archivo de la Catedral de Santiago (a partir de ahora ACS), Fondo general, Actas monásticas de San Martín, 1703-1771, leg. 719, fol. 222. Esta información ha sido publicada en María del Socorro Ortega Romero, "Un proyecto de Fernando de Casas para el tribunal de la Inquisición de Santiago", en Jubilatio. Homenaje de la Facultad de Geografía e Historia a los profesores don Manuel Lucas Álvarez y don Ángel Rodríguez. González, vol. II, Santiago de Compostela, págs. 653-668.
} 
de terreno de la huerta monástica, por lo que los monjes de San Benito paralizaron la obra iniciando un pleito ante el Consejo de la Suprema.

La intervención que pretendía llevar a cabo el Santo Oficio la conocemos gracias a que en el Archivo Histórico Universitario de Santiago se han conservado unas copias del proyecto que había dado Fernando de Casas -catalogadas como planos número 50,51 y $52-$, con las tres plantas del edificio y la fachada principal; y un cuarto diseño (el plano 53) que podría ser uno de los originales de dicho arquitecto (fig. 5) ${ }^{4}$. Junto a éstos se custodian los cuatro dibujos de una segunda propuesta anónima, catalogados como planos 46, 47, 48 y 49, pero que no parece que fuese la aceptada por los inquisidores, ya que su materialización no afectaba a la propiedad de Pinario ${ }^{5}$. El diseño donde se señala la invasión de terreno denunciada por los benedictinos es el número 51 (fig. 4), una copia de la traza para la reforma de la planta baja del palacio -citada como planta primera-, con la ampliación y el lugar por donde corría el muro de la huerta monástica marcado en carmín; pudiendo verse con claridad que el Tribunal se apoderaba de una considerable porción de suelo para la construcción de las dependencias penitenciarias. Según reza su leyenda, el propio Casas y Novoa fue quien facilitó a los monjes la copias del plano para que lo presentasen como prueba ante la Suprema.

La resolución del pleito fue rápida y en mayo de 1727 ambas partes se encontraban próximas a una solución. El enfrentamiento supuso para los monjes la oportunidad definitiva de deshacerse de sus incómodos vecinos, ofreciéndose a conseguir una propiedad a la cual trasladar la nueva sede del Santo Oficio ${ }^{6}$. A

\footnotetext{
4 Estos planos fueron localizados en el Archivo Histórico Universitario de Santiago (a partir de ahora AHUS) por Socorro Ortega, que los dio a conocer en 1987. Recientemente, han vuelto a ser publicados en el catálogo de planos de Galicia en el siglo XVIII, fruto de un proyecto de investigación dirigido por Alfredo Vigo Trasancos. Cfr. Socorro Ortega Romero, "Un proyecto..”; Alberto Fernández González: Fernando de Casas arquitecto en Compostela, Consorcio de Santiago, Nigra Trea, 2008, págs. 182-184; Alfredo Vigo Transancos (dir.), Galicia y el siglo XVIII. Planos y dibujos de arquitectura y urbanismo (1701-1800). Catálogo de planos y dibujos, Fundación Barrié, A Coruña, 2012, pág. 456. Se continuaba así el afán de los inquisidores por mejorar el aspecto y la capacidad de su sede, iniciado en 1709 con el proyecto de remodelación de la fachada principal. Ver Miguel Taín Guzmán, "El urbanismo de Santiago de Compostela: un plano con las plazuelas de San Martín y San Miguel, de 1709”, Espacio, Tiempo y Forma, Vol. 11, 1998, págs. 199-215.

5 Alfredo Vigo Trasancos (dir.), Galicia y..., Catálogo, págs. 457 y 458.

${ }^{6}$ Ya al hablar del establecimiento del Tribunal en Compostela Barreiro señalaba suspicazmente las dificultades que tuvieron para hallar un lugar donde instalar su sede, a pesar del piadoso ambiente de la ciudad. Rodríguez González apuntó que los regulares habían ofrecido a sus vecinos importantes sumas de dinero para propiciar su traslado, pero estas fueron rechazadas al no encontrar los inquisidores un lugar al que desplazarse. Esta aversión hacia el Santo Oficio seguía vigente cuando los monjes de San Martín buscaron una nueva ubicación a sus indeseados vecinos, hasta el punto
} 
comienzos de octubre benedictinos e inquisidores habían alcanzado el acuerdo ${ }^{7}$. El lugar encontrado por los monjes era "la casa que llaman de Calo" (figs. 1 y 2) también llamada Casa Grande del Hórreo, situada en un lugar idóneo para la instalación del Tribunal: extramuros, en un solar con huerta frente a la Porta da Mámoa ${ }^{8}$. Los inquisidores compraban la casa a su dueño, Ignacio de la Vega y Calo, por cien mil reales, y daban a los monjes otros ciento cuarenta mil para llevar a cabo las reformas necesarias; además aforaban a la familia De la Vega "por vida de tres señores Reyes de España" - a contar desde Felipe V-, la Casa de la Penitencia y Cárcel de familiares -es decir, el Palacio de Monterrey-, que debía ser remozado por los religiosos a su propia costa.

A finales de dicho año el abad de San Martín trataba de acelerar la puesta en marcha del acuerdo, proponiendo en el consejo de 15 de diciembre que se buscase a Ignacio de la Vega y Calo una casa cuyo arriendo sería pagado por la comunidad, de manera que pudiera abandonar su vivienda ${ }^{9}$. A la semana siguiente, enviaron al padre Granero y a fray Francisco Velasco a recibir los cien mil reales que el Santo Oficio debía dar al monasterio para comprar el inmueble, escriturar, llevar a cabo la reforma, e informar a los inquisidores acerca de la pensión que podían pedir a Ignacio de la Vega por las casas de la penitencia ${ }^{10}$. Con todo, los benedictinos tardaron más de un año en cumplir lo pactado con la familia De la Vega y acomodar la Casa de la Penitencia ${ }^{11}$. Las obras para adecuar la «Casa de Calo» a su nuevo uso se iniciaron en el primer trimestre de 1728, y una vez concluidas se construyeron "a la parte del norte y calle que bá al convento de

de tener que facilitarles una de sus posesiones en los arrabales de la ciudad. Vid. Bernardo BARREIRO de VÁzquez Varela, "Las casas...”, pág. 253.

${ }^{7}$ Archivo Histórico Diocesano de Santiago (a partir de ahora AHDS), Fondo de San Martín, Varia 78,03 , 28 , s.f. (fol. $14 \mathrm{v}$. y $15 \mathrm{r}$.)

${ }^{8}$ Según quedó reflejado en las Actas Capitulares, el solar sobre el que se había construido la «Casa de Calo» era propiedad de San Martín Pinario. Con todo, las nuevas casas de la Inquisición dieron problemas a los monjes incluso una vez concluida la construcción del complejo. En 1733 los inquisidores reclamaron un precio superior al que habían obtenido por la venta del antiguo edificio, y en 1764 los descontentos herederos de la familia de la Vega interpusieron un pleito a los benedictinos al considerar que habían salido perjudicados con el arreglo alcanzado décadas antes. Cfr. ACS, Fondo general, Actas monásticas de San Martín, 1703-1771, leg. 719, fols. 233 v., 234 r. y 307r. y AHDS, Fondo de San Martín, Varia 78,03, 28, s.f.

${ }^{9}$ Ibídem, fol. 239.

10 Ibíd.

${ }^{11}$ En el Capítulo de 4 de abril de 1729 se leyó un informe redactado por los padres Velasco y Blanco sobre el citado inmueble, y seguidamente se propuso llevar a cabo las reformas necesarias para hacer de la penitenciaría una vivienda familiar. Para ello debían "deshazerle antes las cárzeles y dibidirla después de tabiques hasta ponerla vividera como lo nezesitava un seglar". De cara a este desembolso económico el abad recordó al Capítulo la importancia de esta obra con la que correspondían a lo pactado. Ibídem, fol. 252 r. y v. 
Madres Mercenarias [sic]" varias viviendas para residencia de los ministros de la Inquisición ${ }^{12}$.

En 1764 los herederos de Ignacio de la Vega y Calo denunciaron al monasterio de San Martín Pinario por considerar que había habido "ynormísima lesión y engaño" en la compra de la casa, por la cual habían recibido cien mil reales, mientras que los monjes habían obtenido del Santo Oficio ciento cuarenta mil reales para la compra y obras de acondicionamiento. Por este motivo, estimaban que el valor del inmueble ascendía a la suma de ambas cantidades ${ }^{13}$. En el Archivo Diocesano de Santiago hemos encontrado un legajo procedente de este pleito, con las declaraciones de los testigos de los benedictinos -todos ellos hombres que habían conocido la casa o trabajado en las nuevas casas de la Inquisición-, que aportan interesante información sobre un edificio del que, hasta ahora, apenas teníamos noticias. La demanda obligaba a conocer el estado de la propiedad antes de la venta y tras la reconstrucción, por lo que el tribunal solicitó a los interrogados que realizasen las correspondientes descripciones del inmueble primitivo. Estas aportaciones, hasta el momento inéditas, nos han permitido reconstruir hipotéticamente el inmueble -primero como arquitectura doméstica y luego como palacio de la Inquisición-, pero deben contrastarse con los seis proyectos conservados en el Archivo Histórico Universitario de Santiago en los que, superpuestas sobre la estructura de la «Casa Grande del Hórreo», se representan distintas propuestas para su transformación en la nueva sede del Tribunal y viviendas de sus ministros. Con estas fuentes podemos hacernos una idea muy aproximada de cómo fueron la vivienda de la familia De la Vega y Calo, y el edificio de la Inquisición, derribado en 1913. Para comprender la importancia de reforma del inmueble, comenzaremos analizando la tipología las casas de la Inquisición española y cómo era la sede compostelana en el momento de proponerse la reforma de 1726.

\section{Las casas de la Inquisición y el Palacio del Conde de Monterrey en} COMPOSTELA

El Santo Oficio fue recibido con frialdad por las instituciones gallegas. Las primeras tentativas del Tribunal para instalarse en Santiago tuvieron lugar en 1562 y 1566 , pero dichos intentos fracasaron y no fue hasta 1574 que consiguie-

\footnotetext{
12 AHDS, Fondo de San Martín, Varia 78, 03, 28, fol. 5v.

${ }^{13}$ Ibídem, fols. 2r. y 4v. Las Casas de la Inquisición de la Puerta de la Peña también dieron problemas a los monjes una vez concluida la construcción del nuevo complejo. En 1733 los inquisidores reclamaron un precio superior al que habían obtenido por la venta del antiguo edificio. ACS, Fondo general, Actas monásticas de San Martín, 1703-1771, leg. 719 fols. 233v. y 234 r.
} 
ron asentarse en la región ${ }^{14}$. Entre los problemas hallados por los inquisidores estaba la dificultad para encontrar un inmueble adecuado para su sede, en parte por la escasa disponibilidad de los propietarios a llegar a un acuerdo con la institución. Pero como sucedió en otras ciudades españolas, finalmente encontraron acomodo en el palacio de un noble absentista: el conde de Monterrey, que no disimuló su disgusto al conocer el destino de su propiedad ${ }^{15}$. La tendencia del Santo Oficio a instalarse rápidamente en una localidad y reaprovechar para ello construcciones preexistentes, propició que las casas de la Inquisición no contasen con una tipología arquitectónica propia para sus sedes ${ }^{16}$. Al menos no a nivel estructural, pues el modelo de asentamiento practicado y las específicas funciones que desarrollaron les llevaron a necesitar unas estancias muy concretas, lo que derivó en la creación de un patrón presente en todas sus sedes ${ }^{17}$. Sus edificios debían servir a tres fines: judicial, penitenciario y habitacional. Como tribunal religioso necesitaban de oficinas y aulas, destacando la Sala de la audiencia en la que se interrogaba y juzgaba a los reos. Otras piezas imprescindibles eran la Sala del secreto - nombre derivado de la jurisprudencia canónica secreta que aplicaba la institución-, los despachos de los inquisidores (según su número), antesalas a la audiencia y el secreto en las cuales mantener en espera a presos y testigos, el archivo y el oratorio. Dependiendo del espacio del que dispusieran contaban con más de una sala de audiencia, sala de causas civiles, o de dos archivos (separados según la causa: civil o secreta). Estas dependencias se repartían por el inmueble -veremos que en ocasiones de manera caótica-, pero los salones principales solían ocupar la planta noble. La planta baja y los sótanos se destinaban a penitenciaría. En ellas se instalaban las cárceles y la cámara del tormento, en la que los

\footnotetext{
14 Jaime Contreras, El Santo Oficio..., págs. 23-28 y 35-39.

${ }^{15}$ La casa de la Inquisición de Garganta de la Olla (Cáceres), que se conserva sin apenas transformaciones, había sido la residencia de los condes de Acevedo. En el caso de las casas de Cartagena de Indias uno de los inmuebles adquiridos fue la casa del capitán y regidor Diego de Matute, y en Las Palmas se compraron las casas de los patronos de la obra pía fundada por el canónigo Cervantes. Vid. Manuel Ballesteros Gaibrois, "Nuevos datos para la historia del edificio de la Inquisición en Cartagena", Homenaje a D. Agustín Millán Carlo, Vol. 2, 1975, págs. 325-342; Luis Alberto AnAYa HernándeZ, Rosario Alemán Hernández, "Las casas de la Inquisición de las Palmas y algunas características del tribunal canario", IV Coloquio de historia canario-americana, Vol. 2, 1982, págs. 489-512.

${ }^{16}$ Un edificio de la Inquisición española que se construyó de nueva planta fue el de Cuenca. En los restantes casos se amoldaban a aquellos que conseguían adquirir o que les eran cedidos por instituciones y particulares: Joseph Pérez, Breve historia de la Inquisición en España, Crítica, Madrid, 2009, pág. 131.

${ }^{17}$ Una excepción a tener en cuenta es el palacio del Tribunal de la Suprema en Madrid, que en el último tercio del siglo XVIII se construyó ex novo. No obstante, esta sede respondía a unas necesidades diversas de aquellas que caracterizaron a las casas del Santo Oficio. Véase Luis Carlos Diez Cuevas, El palacio de la Inquisición de Madrid, Imaginógrafo, Madrid, 1998.
} 
inquisidores arrancaban confesiones por el método de la tortura ${ }^{18}$. En ocasiones el tormento también contaba con su antesala, donde se obligaba a los reos a esperar el momento de su suplicio escuchando los lamentos de aquellos que corrían con la peor de las suertes. Se trataba de un método de coacción psicológica, ya que muchos de ellos se decidían a "confesar" a fin de evitar el castigo físico. En algunas casas las cárceles contaban con un lugar para aseo o depósito de las inmundicias. Un elemento frecuente en estos inmuebles era una escalera modesta que comunicaba la prisión con las dependencias del tribunal, evitándose así que los procesados pasasen por la zona noble o pública de la casa ${ }^{19}$. En la planta baja también era habitual encontrar piezas para almacenes, fundamentales para el perfecto desarrollo de la vida de los inquisidores y sus ministros: fiscal, secretarios, provisor, alcaide y portero ${ }^{20}$. Cuando las casas no tenían capacidad para albergar a todos los funcionarios del tribunal eran los inquisidores y el fiscal con sus sirvientes los que residían en ellas, pero el ideal de un palacio de la Inquisición era acoger a todo su personal, por lo que se necesitaba de un considerable espacio. A las bodegas y graneros había que añadir caballerizas, piezas para el servicio -que solía habitar los entresuelos y el entorno de las cocinas-, las cámaras de uno o más inquisidores, y las estancias de los ministros, que se repartían por los pisos altos del inmueble. Dado el elevado número de moradores, la tendencia era a buscar un edificio que contase con uno o más patios, huerta, o jardín que lo hiciesen más habitable, salubre, y que diese a sus habitantes la posibilidad de autoabastecerse de ciertos alimentos. En ocasiones los inquisidores hacían una primera reforma en el momento previo a su instalación -especialmente para acondicionar las cárceles- y trataban de acomodar las piezas preexistentes a los diversos usos ${ }^{21}$. Esto daba un aspecto irregular y por lo general poco funcional a sus palacios, lo que motivaba posteriores reformas como las pensadas en $1610 \mathrm{y}$ 1726 por el Santo Oficio compostelano ${ }^{22}$.

\footnotetext{
${ }^{18}$ En este espacio se disponían instrumentos tristemente famosos como el potro, la polea, el ataúd, látigos, etc. que fueron prontamente denunciados por los detractores de los métodos de Santo Oficio. Reginaldo González Montes, Artes de la Inquisición española. Almuzara, Córdoba, Almuzara 2010 ( $1^{\text {a }}$ ed. Heidelberg, 1567).

19 Acerca del proceso que padecían los presos de la Inquisición véase Joseph Pérez, Breve historia..., págs. 121-158.

${ }^{20}$ El número de funcionarios podía variar según el tamaño de dicho tribunal, y ciertas actividades recaer sobre un único cargo. Cfr. Jaime Contreras, El Santo Oficio..., págs. 307-317; Joseph Pérez, Breve historia..., págs. 103-108.

${ }^{21}$ En Cartagena de Indias se hizo una primera intervención y pasado el tiempo se adquirieron las casas anejas para ampliar el complejo y aglutinar en él a todos los ministros. Manuel BaLLESTEROS Gaibrois, "Nuevos datos...", pág. 329.

22 Lo mismo sucedió en Las Palmas donde, como en Santiago, la institución buscó potenciar su imagen de poder. Luis Alberto Anaya Hernández, Rosario Alemán Hernández, "Las casas...", págs. 500-510.
} 
Sobre cómo era la planta de las primeras casas de la Inquisición en Santiago podemos hacernos una idea gracias a que Barreiro de Vázquez Varela reprodujo y dio a conocer en 1883 un dibujo localizado en Simancas (fig. 3) que más tarde Contreras localizó en el Archivo Histórico Nacional, y que publicó en su estudio sobre el Tribunal gallego ${ }^{23}$. Según estas fuentes, el palacio se organizaba en tres alturas y era suficientemente capaz como para albergar a los dos inquisidores, proveedor y alcaide. No obstante, sus 21 cárceles, dos salas de audiencias, habitaciones y salas privadas, estudios y almacenes, se distribuían de manera más bien anárquica en incómodas estancias. La falta de orden y las estrecheces con las que se veían obligados a vivir diariamente impulsaron la reforma de 1726, con la que también pretendían potenciar la imagen oficial de una institución que había dejado atrás su época de esplendor. Por este motivo, tanto la propuesta de Casas y Novoa como el proyecto anónimo se centran en estructurar la zona suroccidental del inmueble donde se ubicaban las salas del tribunal y las cárceles, y proponen una nueva fachada principal. De Fernando de Casas sólo se conserva la traza de la planta baja del inmueble (fig. 5) con un primer piso de cárceles, el "castigo secreto" (que debía equivaler al tormento), el vertedero, oficinas o almacenes de alhajas, y una nueva entrada que culminaba en una escalera noble para acceder a las oficinas principales y la sala de audiencias que, como se puede intuir por la copia de las trazas que tenían los benedictinos, se encontrarían en el piso principal. La crujía occidental, que era la destinada a albergar los dos pisos de calabozos, fue la que motivó el pleito con los monjes de San Martín Pinario y que la construcción de un palacio adecuado se llevase a cabo en la casa de la familia De la Vega y Calo.

\section{La Casa Grande del Hórreo o de Calo}

Según el pleito de 1764, la familia de Ignacio de la Vega le compró la «Casa Grande» de la Porta da Mámoa -en la esquina que hoy forman la rúa do Hórreo y rúa da Fonte de Santo Antonio- a María de Calo y Temes en $1698^{24}$. Esta mujer se había instalado en allí con su familia en el último cuarto del XVII, pero se vio

\footnotetext{
${ }^{23}$ Ignoramos la fecha de este dibujo por lo que no sabemos si es posterior a la reforma de 1607, que se emprendió para intentar paliar la incomodidad del inmueble. Cfr. Bernardo BaRREIRo DE VÁzqUEZ Varela, "Inquisición de Galicia...", y Jaime Contreras, El Santo Oficio..., págs. 329, 354 y 355.

${ }^{24}$ Junto con su marido, el regidor compostelano Martínez de la Vega, María de Calo había llevado a cabo una interesante labor de mecenazgo artístico, ella financiando la capilla de Santa Teresa de la iglesia de Salomé y él atesorando una considerable colección de pintura. Ver María Agustina Fernández Álvarez, Arte y sociedad en Compostela, 1660-1710, Sada, Edicións do Castro, 1996, págs. 37, 51, 196, 197 y 210.
} 
obligada a vender la propiedad por problemas de hacienda ${ }^{25}$. Hacia 1692 el inmueble se describe como "casa nueva... con su güerta, bodegas, altos y vajos"; sin embargo, el costoso mantenimiento del inmueble hizo que las descripciones del XVIII lo presentasen como un proyecto a medio acabar y con un aspecto irregular: de apariencia noble en sus dos fachadas principales pero modesta en aquellas crujías que daban a la huerta y los espacios privados. En el momento en que vendió la casa a los inquisidores la familia únicamente habitaba parte del inmueble. Su estado era de relativo deterioro y tenía algunos de los almacenes y caballerizas alquilados ${ }^{26}$. La documentación hallada no aclara en qué momento se construyó el edificio, aunque algunas noticias relacionadas con la Tenencia del Hórreo podrían indicar que ya estaría en pie hacia 1658 y que las reformas posteriores se dieron a partir de esta estructura ${ }^{27}$.

La mayoría de los testigos que en 1764 describieron la casa de la familia De la Vega la habían conocido durante su niñez o en su juventud ${ }^{28}$. A pesar de que los testigos hicieron un ejercicio de memoria, y por tanto sus relatos padecen de lagunas y deformaciones, el número de declaraciones y la cantidad de detalles que aportan bastan para permitir que nos hagamos una idea bastante precisa de cómo era antes de la reforma, que apenas afectó a las fachadas y al perímetro del edificio. La casa tenía una planta cuadrangular y amplio patio interior que

\footnotetext{
${ }^{25}$ Según las actas capitulares de San Martín Pinario, la propiedad del solar correspondía a los benedictinos, que también eran dueños de las casas que ocupaban el terreno contiguo en la calle del Hórreo. En las actas del Capítulo catedralicio de 7 de marzo de 1680, se acuerda la visita a la obra realizada por María de Calo en una casa de propiedad capitular que formaba parte de la Tenencia del Hórreo y que, entendemos, debía de ser la que nos ocupa. Esta información contrasta con lo declarado por los benedictinos, quienes en sus documentos se atribuían la posesión de la Casa de Calo y su solar. No obstante, cabe la posibilidad de que la propiedad del terreno estuviera repartida entre ambas instituciones, en un caso similar al de la Casa del Cabildo. Cfr. ACS, Actas capitulares, leg. 629 , fols. 152 v y 159 r. y v.; leg. 630, fols. 23 v. y 24 r., ACS, Fondo de San Martín, Actas Capitulares, 1703-1771, leg. 719, fol. 23v. y 24 r.; AHDS, Fondo de San Martín, Varia 78,03,28, s.f. Sobre el solar de la Casa del Cabildo véase Miguel Taín Guzmán, La Casa del Cabildo de Santiago de Compostela (1754-1759): "pro commoditate ac ornato urbis", Electa, Consorcio de Santiago, 2000, págs. 15-17.

${ }^{26}$ AHDS, Fondo de San Martín, Varia 78,03,28, s.f.

${ }^{27}$ ACS, Casas y tenencias, leg. 168, fol. 85r.

${ }^{28}$ Entre ellos había varios maestros que habían trabajado en la reforma posterior como Julián de la Dehesa (sobrestante) y Agustín Marante (cantero), que estudiaron en el Colegio de Ejercitantes de los Jesuitas e iban a jugar a la pelota al claustro o patio asoportalado de la citada casa; Antonio de Lago (ensamblador) que era vecino del barrio del Hórreo; y Francisco Caniña (carpintero) que de niño había sido sirviente en el convento de las Mercedarias, estrechamente vinculado a la familia de la Vega. Junto a ellos declararon otros testigos como Tomé de Villaverde, un carpintero que -como los citados de la Dehesa y Marante- había sido colegial de los Jesuitas; Pascual Martínez, que conoció la casa de niño por vivir en las inmediaciones, y Marcos Nogueira que era nieto de la mujer encargada de cultivar la huerta de la Casa.
} 


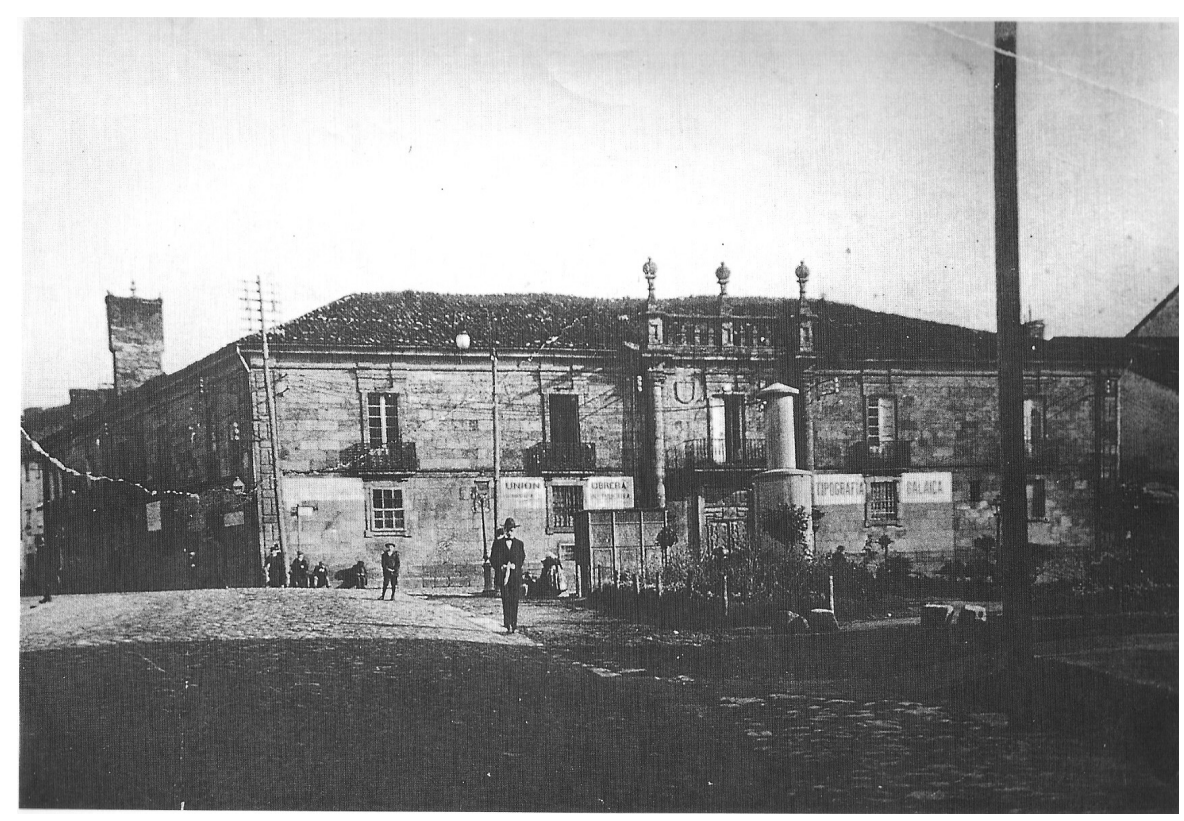

Fig. 1

Casas de la Inquisición de Santiago, c.1909

distribuía las dependencias en cuatro crujías de dos pisos. Los frentes meridional y oriental daban a la huerta y eran de mampostería a excepción de la cornisa que recorría el perímetro del edificio y las ventanas, todas de cantería. En ellos los vanos eran modestos, prescindiéndose de los elementos que ornaban las fachadas principales: la occidental, que daba a la rúa do Hórreo, y la septentrional, que corría paralela a la actual rúa da Fonte de Santo Antonio. Ambas estaban construidas en cantería y jalonadas de puertas-balcones en su planta alta. $\mathrm{Su}$ aspecto podemos conocerlo gracias a fotografías tomadas antes de la demolición del edificio, ya que apenas sufrieron transformaciones durante la reforma dieciochesca (figs. 1 y 2). En ellas se daba un predominio del desarrollo en horizontal, resaltado por la línea de imposta que las dividía en dos registros, y la plasticidad de sus ángulos se reforzaba con pilastras almohadilladas de orden gigante. La fachada principal era la occidental (fig. 1). Su preeminencia quedaba reflejada en la portada que dominaba su eje central. Se componía de un par de columnas gigantes de orden clásico (imposible de determinar) elevadas sobre altos pedestales recortados, aupados a su vez sobre un zócalo que recorría la parte baja del edificio. Dichas columnas sostenían sendos fragmentos de entablamento y sobre la cornisa, ocupando el ancho de la portada, el conjunto se remataba con 
una balaustrada de dos tramos delimitados por mesetas sobre las que se erigían esbeltos pináculos en bola. En su interior se disponían la puerta de entrada -con sobria guarnición- y sobre ella el característico balcón ${ }^{29}$. El resto del frente se articulaba en dos mitades simétricas, cada una de ellas con un par de ventanas con guarnición de cantería en la mitad inferior, y a eje con ellas en el piso principal las características ventanasbalcón (citadas en la documentación como "puertas balcones”). El aderezo de los vanos se prolongaba sobre los

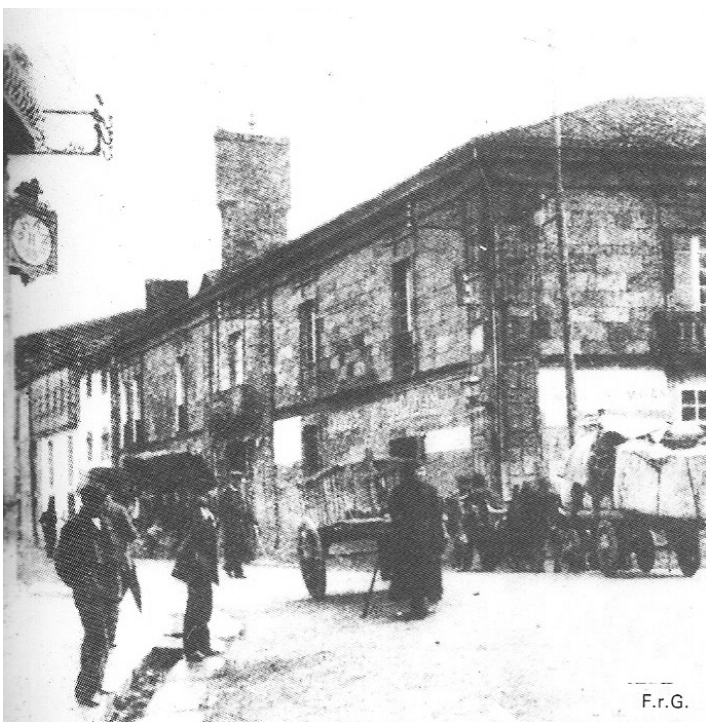

Fig. 2

Casas de la Inquisición de Santiago. Fachada norte cuadrantes superiores hasta enlazar con la imposta -en la planta baja-, y con el entablamento - en la alta.

La fachada septentrional (fig. 2) presentaba una composición semejante a la occidental: con predominio del desarrollo horizontal, articulada en dos registros mediante imposta, y con las pilastras gigantes almohadilladas en los ángulos soportando la cornisa. El centro de la fachada lo presidía una portada más modesta que la principal. Se hallaba delimitada por un par de pilastras gigantes semejantes a las angulares; en la planta de acceso se disponía la puerta y sobre ella, en el registro superior, un balcón poco volado. En las imágenes diversos objetos limitan la visión de la planta baja, donde únicamente vemos dos ventanas y una tronera en el ángulo noroccidental. Quitando este elemento, los vanos y sus molduras son iguales a los de la cara principal; y lo mismo sucede para las cuatro ventanas-balcón del piso alto. Lo registrado en estas fotografías contrasta con las descripciones de algunos testigos, que hablan de dos puertas en la fachada norte, y por cuyas declaraciones se deduce que eran puertas de acceso a los almacenes

\footnotetext{
${ }^{29}$ Las fotografías conservadas muestran que a ambos lados del balcón se disponían sendos escudos, pero no permiten distinguir las armas de estas piezas, de manera que no sabemos si eran de tiempos de la obra primitiva o si pertenecían al Santo Oficio, siendo en este caso el escudo real y el de la Inquisición.
} 


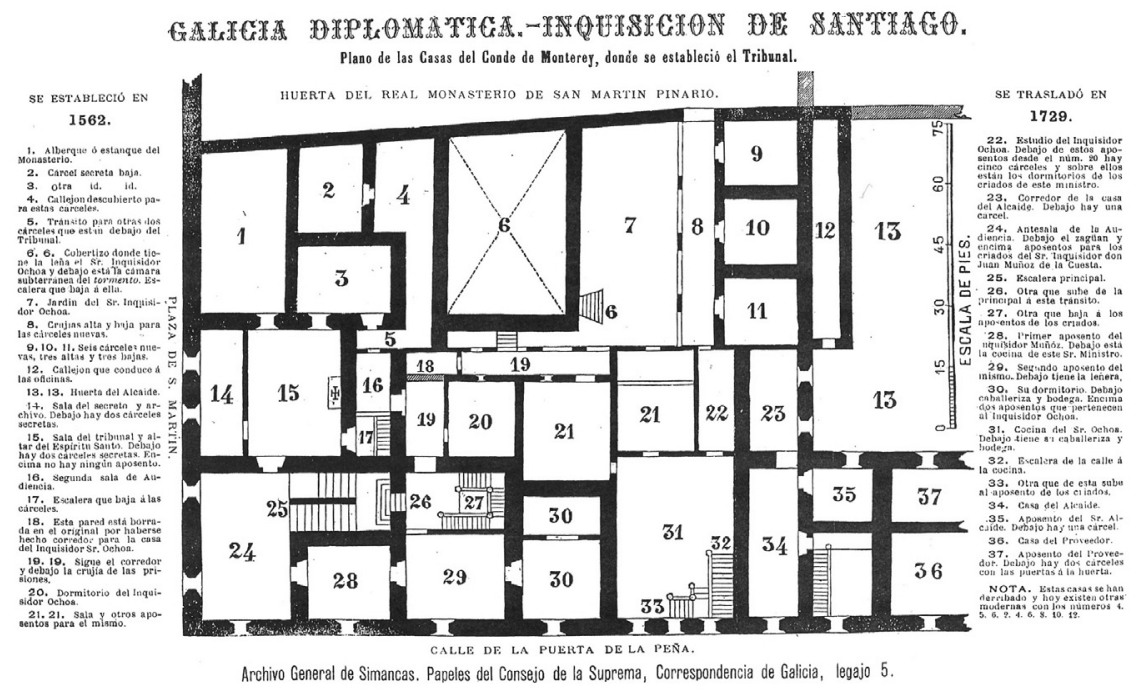

Fig. 3

Plano de las casas de la Inquisición en el Palacio de Monterrey según Barreiro de Vázquez Varela. Galicia Diplomática. T. 1

que había en esta ala ${ }^{30}$. Otro elemento destacado en esta fachada es la gran chimenea, que a pesar de ser de mampostería y carecer del componente estético que presentan las de otros edificios representativos de la ciudad, llama la atención por su tamaño. No obstante, veremos que no formaba parte de la construcción primitiva, añadiéndose en la reforma del XVIII.

Exteriormente el edificio tiene poco que ver con las «casas grandes» y palacios de la ciudad de Compostela pero presenta ciertos ecos de otra importante construcción ubicada extramuros: el Colegio de San Clemente, diseñado en la primera década del XVII por el maestro Jácome Fernández, padre ${ }^{31}$. Si bien es cierto que el clasicismo es menos depurado en la Casa de Calo -donde la articulación de la portada en tres calles y dos órdenes, y el componente ornamental del Colegio compostelano se ven muy simplificados-, no lo es menos que el

\footnotetext{
30 Véanse las declaraciones de Francisco Caniña, Agustín Marantes, Pascual Martínez y Marcos Nogueira en AHDS, Fondo de San Martín, Varia 78,03,28, s.f.

${ }^{31}$ Sobre el Colegio de San Clemente de Pasantes véanse Antonio Bonet CorReA, La arquitectura en Galicia durante el siglo XVII, CSIC, Madrid, 1984 (2 $2^{\mathrm{a}}$ ed.), págs. 127-130; Sebastián GonZÁLez García-Paz, O Colexio de San Clemente de Pasantes de Compostela. Consorcio de Santiago, Universidade de Santiago, Santiago de Compostela, 1993 y José Manuel García Iglesias (dir.), Compostela e o Colexio de San Clemente de Pasantes, Xunta de Galicia, 2004.
} 


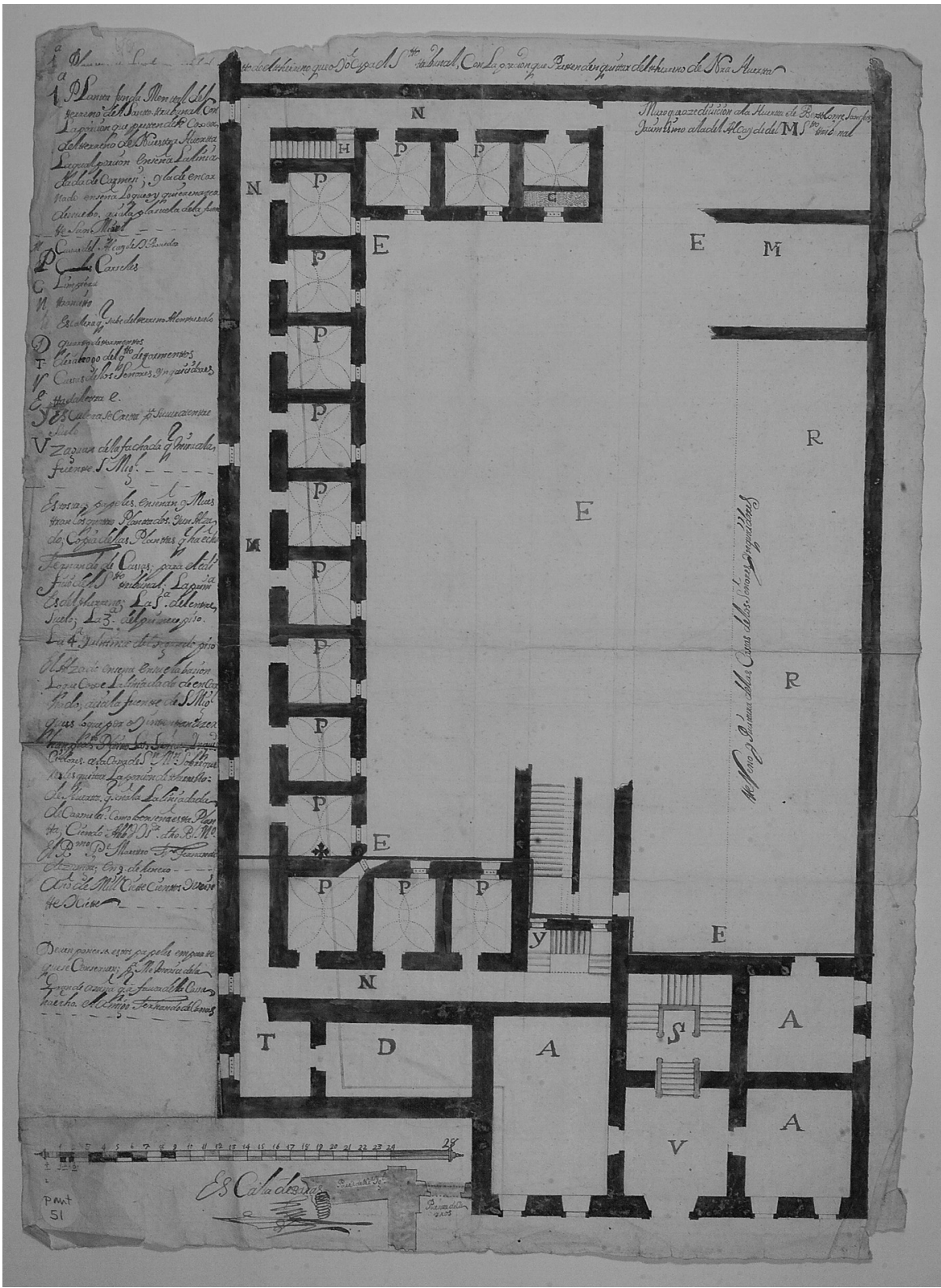

Fig. 4

Copia del proyecto de Casas y Novoa para la ampliación de la primera planta del palacio de la Inquisición en la Plazuela de San Miguel, c. 1727. AHUS, Planos nº 51. 


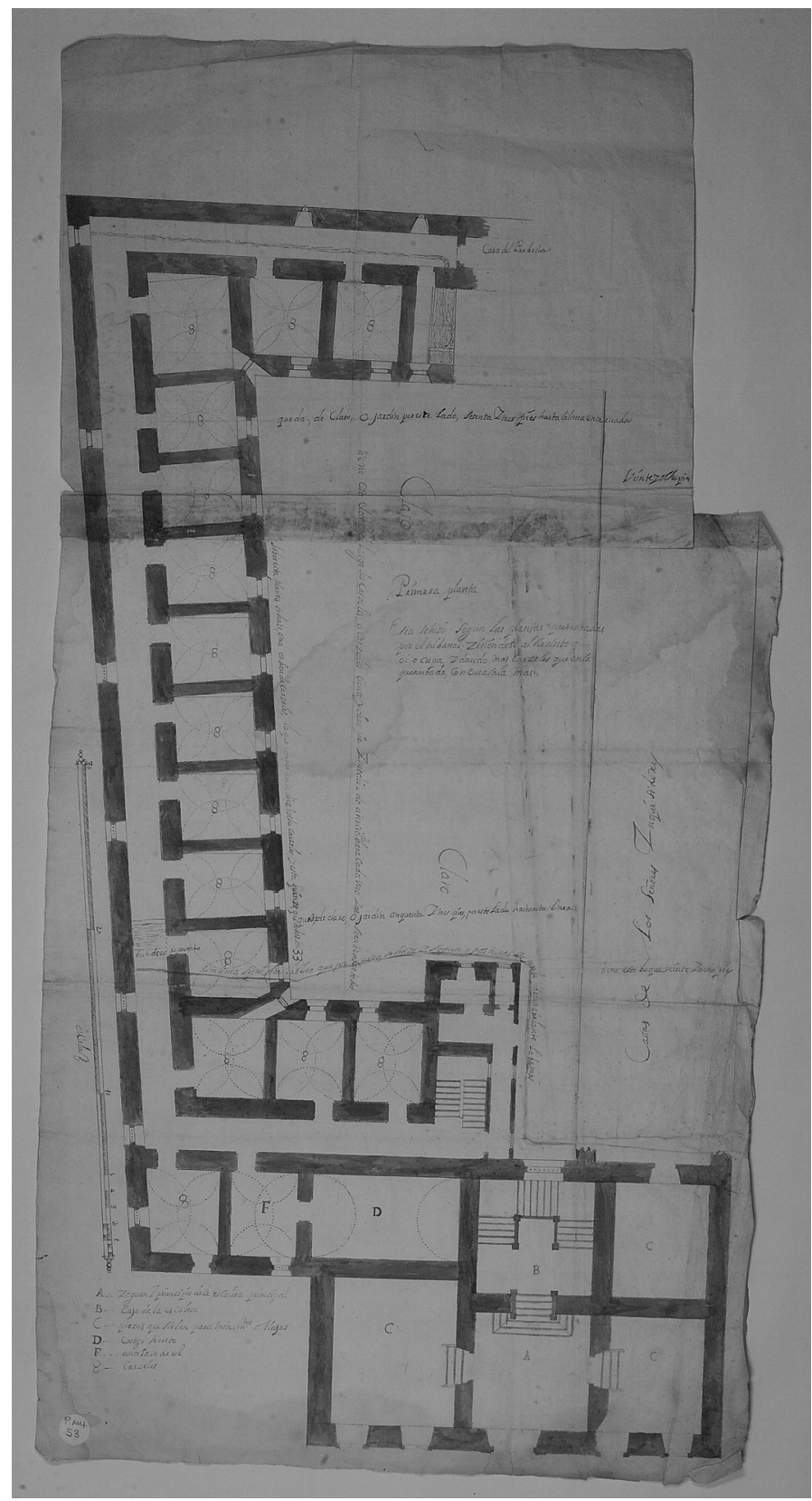

Fig. 5

Fernando de Casas y Novoa. Proyecto de ampliación de la primera planta del palacio de la Inquisición en la Plazuela de San Miguel, c. 1726. AHUS, Planos, n 53 
recuerdo a esta obra en el desarrollo de la fachada, y la disposición axial de la portada articulada mediante los soportes, es casi inmediato. En la casa el clasicismo aflora en el predominio de la horizontalidad, la axialidad y la simetría que domina la composición de los frentes, en su tratamiento plástico, la contención de los efectos lumínicos y la escasa ornamentación, que nada tienen que ver con las fachadas diseñadas por los arquitectos barrocos a partir de la segunda mitad del XVII y hasta bien avanzado el siglo XVIII. Las pilastras almohadilladas, por su parte, recuerdan a la articulación del segundo piso del Claustro de Oficinas de San Martín Pinario - cuya traza se ha atribuido a Peña de Toro-, y dado que según los testigos las fachadas principales se conservaron sin apenas modificaciones, el autor de la «Casa de Calo» debió de ser un maestro compostelano activo en el último tercio del siglo XVII ${ }^{32}$.

El interior del edificio sólo podemos reconstruirlo a partir de las declaraciones de los testigos del pleito. La puerta occidental era la única entrada a la vivienda. A través de ella se pasaba a un zaguán y desde éste al patio central, que servía como distribuidor. En la planta baja del patio se disponían "diferentes piezas y oficinas para bodegas, granería, cavallerizas y más servicio de

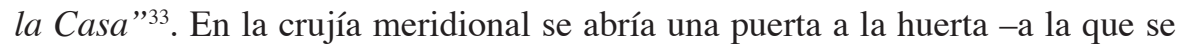
llegaba atravesando un segundo zaguán-, y frente a ésta, en la panda norte, se disponía la escalera de subida a la planta alta que era la única de la vivienda ${ }^{34}$. Todos los testigos describen la escalera y coinciden en señalar que era espaciosa, de cantería y sin balaustres ni barandilla. Por lo que comentan Pascual Martínez y Nogueira, no necesitaba de ella ya que corría encañonada entre paredes "sin güeco alguno" 35 . Desde el desembarco de la escalera se llegaba a un corredor de madera que discurría por los lienzos septentrional y occidental del claustro dibujando una ochava. Este pasadizo consistía en un balcón sostenido por "canzorros o nudillos”, con antepecho en leño y una cubierta de teja que continuaba por las paredes este y sur del patio, resguardándolo parcialmente de la lluvia ${ }^{36}$.

32 María Dolores VILA JATO, "El Monasterio. La Edad Moderna”, Santiago. San Martín Pinario. Santiago, Xunta de Galicia, 1999, pág. 192.

33 Así lo cuenta Pascual Martínez, aunque los restantes testigos informan en el mismo sentido. Algunos cuartos habían sido alquilados a mercaderes asturianos para almacenamiento de sus géneros, otros para almacén de grano de la tropa Militar, e incluso uno había servido para cochera del arzobispo Esgueva. AHDS, Fondo de San Martín, Varia 78-03-28, s.f. (fols. 8v., 9r. y v.)

34 Únicamente había una escalera de servicio de madera que comunicaba la bodega con la cocina en la panda sur.

35 Ibídem, s.f. (fols. 9r. y 9v.)

36 Según Pascual Martínez "estaba sostenido de unas viguetas que firmaban en las Paredes por la parte de el Claustro, Pontones y piso de madera, en forma de tal tenía su antepecho de tablas; de Largo cosa de diez codos que componen cinco baras y de a ocho junto al desembarco de la escalera 
Los testigos cuentan que era el medio de acceso a la antesala de la panda oeste, a partir de la cual se podía circular hacia el resto del edificio.

El espacio destinado a la vivienda familiar se concentraba en el primer piso y era suficiente para albergar a un elevado número de inquilinos. En las primeras décadas del siglo XVIII la habitaban Ignacio de la Vega y Calo, su esposa, sus cuatro hijos, y varios parientes de la señora de la casa: José y Ana Margarita Vallo de Porras -sus tíos-, y sus hermanos: Jacinto, Andrés y Juan Francisco Vallo de Porras, este último prior dignidad de la Iglesia de Santiago. A la familia la acompañaban un capellán, dos pajes, un criado, dos criadas, y un ama que dio pecho a los niños mientras fue necesario. Con todo, parte de la casa (hacia levante y mediodía) permanecía cerrada. Según recordaba Nogueira, en el ángulo suroriental se encontraba el oratorio, con ventanas a la huerta en sus dos fachadas. Parece que en el oratorio había un acceso a las restantes estancias de la panda oriental, pero al momento de la venta de la casa los vanos estaban tapiados, lo que sugiere que esa ala se hallaba en desuso. La cocina se encontraba en el sur, con la tradicional chimenea con trabateles y cambota de cantería, y en torno a ella se encontraban también las cámaras del servicio ${ }^{37}$. Los declarantes coinciden en señalar que las salas nobles daban a la fachada occidental.

Por la tipología de casa con patio, las dimensiones, y las estancias que citan los testigos, nos hayamos ante una "casa principal”, definida por Blasco Esquivias como "aquella que constituye para la mayoría de usuarios una morada definitiva y desahogada, culminación a veces de toda una carrera de traslados" 38 . Se trata de la vivienda de una familia acomodada - como fue la de María de Calo- que, sin ser necesariamente palaciega, cuenta con las estancias necesarias para llevar una vida pública y privada desahogada. En Santiago de Compostela la casa con patio proliferó a partir siglo XVI, conservándose planos con diversos ejemplos en los archivos de la ciudad ${ }^{39}$. Con todo, la mayoría eran viviendas estrechas en las que el patio se desplazaba hacia uno de los laterales del solar al tiempo que las habitaciones se distribuían en tres de sus caras. En este sentido,

\footnotetext{
y donde principiaba cosa de bara y media pero menos ynmediato a la Puerta donde concluirhía [sic] porque hiría en diminución". Ibídem, s.f. (fol. 9r.)

${ }^{37}$ El único testigo que habló de la existencia de una chimenea en la crujía norte es Agustín Marante, pero comenta que no había cocina. Ibídem, s.f. (fols. 7r. y 10 r.)

${ }^{38}$ Beatriz Blasco Esquivias, "Los espacios de la necesidad: alimentación, higiene y descanso nocturono" en Beatriz Blasco Esquivias (dir.), La casa. Evolución del espacio doméstico en España, Vol. 1, Ediciones El Viso, Madrid, 2006, pág. 46.

39 Vid. Andrés Rosende Valdés, "La imagen urbana de Compostela en tiempos de Carlos V", en Antonio Eiras Roel (coord.), El reino de Galicia en la época del emperador Carlos V, Santiago de Compostela, Xunta de Galicia, Consellería de Cultura Comunicación Social e Turismo, Dirección Xeral de Patrimonio Cultural, 2000, págs. 655-656.
} 
la «Casa Grande del Hórreo» se ajusta mejor al modelo de palacio compostelano articulado mediante un patio porticado de disposición central cuyo arquetipo surgió en el siglo $\mathrm{XVI}^{40}$. De este periodo conservamos el Palacio del cardenal Mondragón o el del Marqués de Santa Cruz, ambos en la Rúa Nova; pero este esquema lo tuvieron otros edificios como el Palacio de los Condes de Altamira ${ }^{41}$, la casa número 16 de la Rúa Nova -trazada por Domingo de Andrade-, la Casa das Pomas de Diego de Romay, o la Casona de la Rúa de Bautizados propiedad del alguacil mayor del arzobispado Gómez de Rioboo ${ }^{42}$.

\section{Las nuevas casas del Santo Oficio en la Porta da Mámoa}

El que acabamos de describir era el estado de la Casa de Calo en el momento de su venta pero, como comentamos, antes de que los ministros del Santo Oficio se trasladasen al nuevo edificio fue preciso adaptarlo a su nueva función. Las transformaciones realizadas también fueron relatadas por los testigos del pleito dado que la mayoría de ellos trabajaron en sus talleres o conocieron el inmueble de la Inquisición después de las reformas. La solución adoptada fue la propia de esta institución: se reaprovechó la estructura esencial del edificio concentrando los principales cambios en la reorganización de los espacios internos y en la construcción a fundamentis de las cárceles y las casas para los funcionarios del Tribunal.

Según los testimonios la obra comenzó en 1728 y se terminó entre 1731 y $1732^{43}$. El maestro de obras encargado de la fábrica fue fray Francisco Velasco y el aparejador su correligionario fray Íñigo Suárez. Éste tuvo de inmediatos subalternos a Bartolomé Sieiro, maestro de carpintería, y Francisco de Moure, de mampostería. Terminadas las reparaciones el hermano Suárez abandonó la fábrica para atender otras obras en Pinario, siendo sustituido en su puesto por Sieiro,

\footnotetext{
${ }^{40}$ Miguel TAín Guzmán, Domingo de Andrade, maestro de obras de la catedral de Santiago (16391712), Sada, Edicións do Castro, 1998, pág. 302.

41 Véase el plano del Plano del Palacio de Altamira conservado en AHUS, Fondo Municipal, Abastos. Obras en la Pescadería, Carnicería, Plaza da Abastos y Alhóndiga (1832-1862), fo.. 270; a partir de Andrés Rosende VALDÉs, Unha historia urbana, Compostela 1595-1780, Vigo, Nigra Trea, 2004, pág. 154.

42 Miguel Taín Guzmán, Domingo de Andrade..., págs. 298-302.

43 Julián de la Dehesa y España, que fue contratado como listador o sobrestante por el padre Velasco en 1729, trabajó en las Casas de la Inquisición hasta la conclusión de los trabajos, que dató en 1731, pero el carpintero Antonio Lago la da por concluida un año más tarde, y esta fecha parece corroborarse con la información de las Actas Capitulares de San Martín, ya que fue en el consejo de 13 de mayo de 1732 cuando se aprobó la elección de maestros para el reconocimiento final de la obra. Ibídem, s.f. (fols. 4v. y 6v.) y ACS, Fondo General, Actas de San Martín Pinario 1703-1771, leg. IG719, fols. $287 \mathrm{v}$. y $288 \mathrm{r}$.
} 
que ejerció de aparejador de las casas para los ministros ${ }^{44}$. Cuentan los testigos que el taller se componía de un máximo de ochenta hombres, algunos de ellos llegados de fuera de la ciudad ${ }^{45}$. A estos nombres podemos unir los de Diego Chico, Domingo Calbelo y Andrés Martínez, que ya habían fallecido en 1764; Antonio García, Antonio Lago, Agustín Marante, Francisco Caniña, Tomé de Villaverde, Domingo López, Pascual Martínez y Marcos Nogueira -testigos del pleito-, así como el del escribano que diariamente tomaba nota de los oficiales que concurrían a la fábrica: José González Taboada, que había dejado Santiago para trasladarse a vivir a Carboeiro ${ }^{46}$. Del mismo modo que el padre Velasco llamó al aprendiz Julián de la Dehesa, fray Íñigo Suárez contrató al cantero Agustín Marante, que por entonces trabajaba en la Capilla de Nuestra Señora de los Ojos Grandes de Lugo ${ }^{47}$.

Como comentamos al analizar la «Casa de Calo», la reforma apenas afectó a las fachadas principales del inmueble; únicamente algunas de las puertas-balcones originales se transformaron en ventanas, dando al edificio un aspecto menos abierto y más adecuado a su nueva función ${ }^{48}$. Por las fotografías de comienzos del siglo XX, no queda claro dónde se llevó a cabo esta intervención. Los vanos del piso terreno presentan ventanas mientas que los de la planta alta ventanasbalcones, de manera que la reforma sólo parece evidente en la tronera del piso terreno del frente septentrional. La información de los declarantes es poco precisa, pues no se ponen de acuerdo sobre el número de ventanas modificadas, ni

\footnotetext{
${ }^{44}$ En palabras de Antonio Lago, ensamblador que actuó como testigo en este pleito: “... cuando (...) entró a travajar en ella hera su aparejador un Monje Lego de dicho Real Monasterio de San Martín llamado fray Ynigo y listador o sobre estante [sic] Julián de la deHesa que [...] en algunas oras libres se empleaba en diliniar y dibujar en papeles pertenecientes al de Arquitectura en el que se enseñaba y dirixía dicho Padre Maestro Velasco; y por haver sido preziso al Padre frai Ynigo asisitir a una ôbra que se ha ofrezido en el Monasterio, después de fenezida la que se hizo en la Casa de la disputa, en su lugar entró Bartholomé Sieyro por Aparejador de las Casas que se han fabricado pegado a la de la disputa a la parte del norte y calle que bá al convento de Madres Mercedarias, en las que viven algunos Ministros del Santo Oficio, y en que ejerció dicho deHesa el mismo empleo y de Maestro el Padre Velasco, quien pagaba a los travajadores y Materiales de una y otra obra ...”. Ibídem, fol. 5v.

${ }^{45}$ Ibídem, fol. 4r.

${ }^{46}$ Ibídem, fol. 6v.

${ }^{47}$ Es posible que Suárez hubiera trabajado junto a Marante en Lugo, donde había sido aparejador del claustro catedralicio; o incluso que hubiera sido Fernando de Casas, que además de ser el autor de la Capilla de la Virgen de los Ojos Grandes tenía una buena relación con los maestros benedictinos, quien lo recomendó. Ibídem, fol. 7r.
}

48 "Todas las Ventanas que tenía la Casa heran rasgadas o por otro nombre Puertas Balcones y aunque tenían sus antepechos de Balaustres de fierro con sus baras y las ventanas de madera por la parte exterior y que estas se allavan de servicio, se han quitado dicho Balaustres que sirvían de antepechos y sen puesto de Cantería reduciendo con ello dichas Puerta Ventanas, solamente a ventanas...”. Ibíd. 


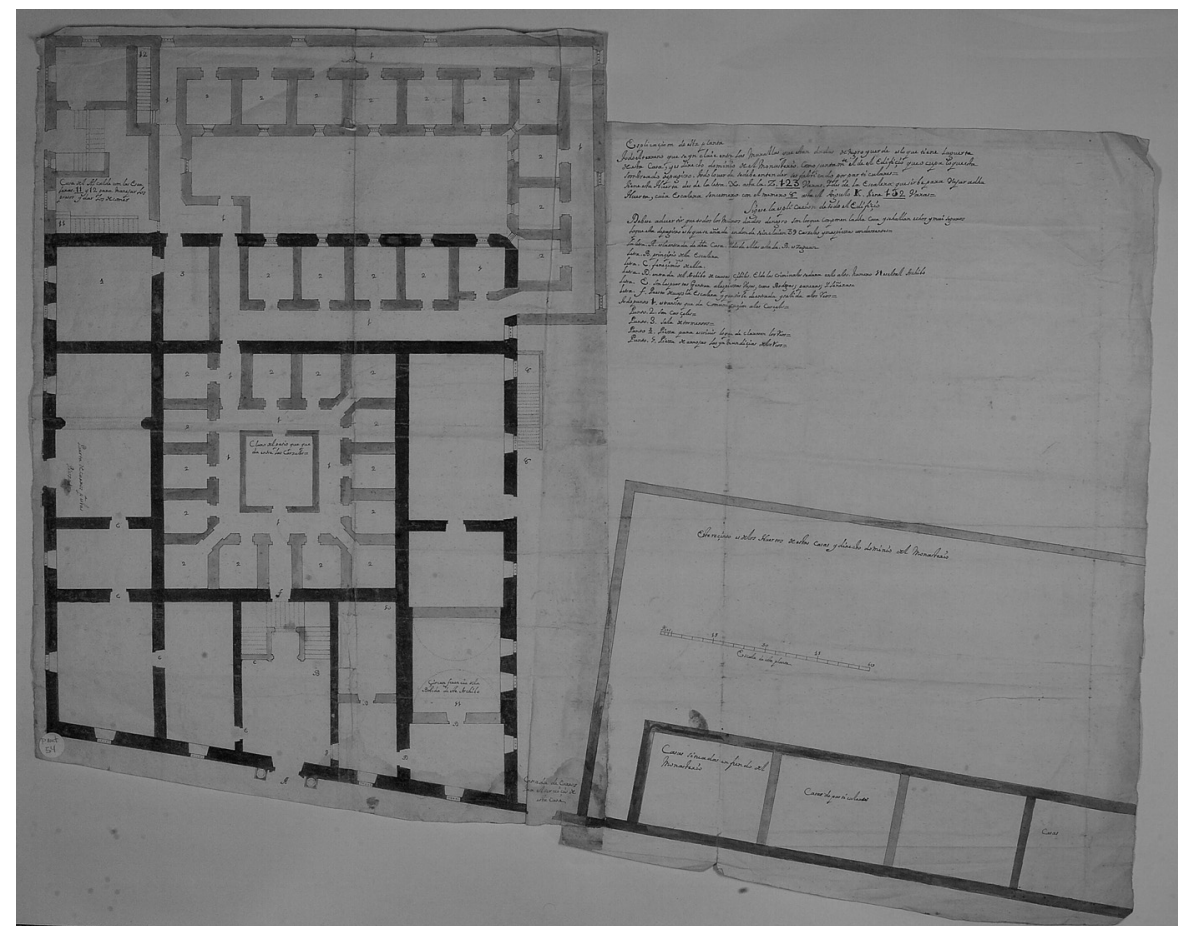

Fig. 6

Anónimo. Proyecto de reforma de la planta baja de la Casa de Calo para palacio de la Inquisición, c. 1727 . AHUS, Planos n ${ }^{\circ} 54$

concretan cuáles se transformaron. Pero si confrontamos estas noticias con los diseños para la reforma de la casa vemos que el lienzo norte presentaba entre seis y nueve ventanas en la planta baja, y siete en la superior (figs. 6, 8-10); por lo que fue esta fachada la que se remodeló para igualar su composición con la occidental, aunque no necesariamente tal y como describen los testigos. Aprovechando estos trabajos enlosaron la acera de ambos frentes y delimitaron la propiedad del Tribunal en el espacio correspondiente a la tradicional lonja: al norte mediante postes de cantería y al oeste con "pixamedes" o columnas de cantería con remates (fig. 12) ${ }^{49}$. Parece que en las fachadas meridional y oriental los cambios tampoco fueron sustanciales, con la excepción de la apertura de pe-

49 Como explica Rosende Valdés, este elemento era característico de los edificios señeros de la ciudad, que tendían a acotar mediante este sistema sus propiedades. Vid. Andrés RosendE VaLdés, Unha historia urbana..., págs. 151-165. 


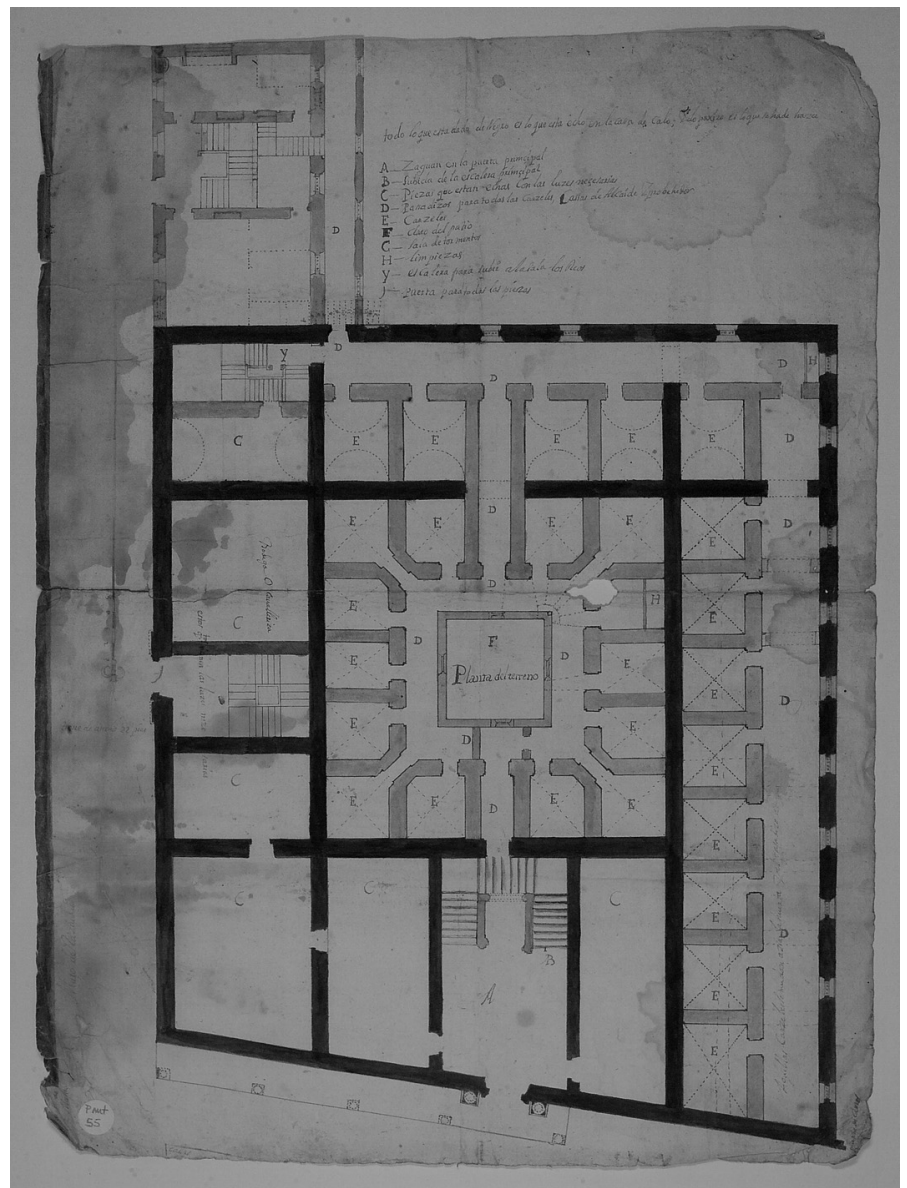

Fig. 7

Anónimo. Proyecto de reforma de la planta baja de la Casa de la Calo para palacio de la Inquisición, c. 1727. AHUS, Planos n ${ }^{\circ} 55$

queños vanos para la iluminación de las celdas que se construyeron en la planta baja del inmueble.

La intervención más profunda se dio en el interior, que debía organizarse como penitenciaría, tribunal y vivienda. La principal transformación fue la del claustro, que quedó reducido a luneta o "media luna” para albergar parte de los calabozos. Caniña y Villaverde declararon que las paredes de este nuevo patio se cerraron con cantería, mientras que Domingo López afirmó que este material sólo se empleó en el piso superior mientras que el inferior era de mampostería de pizarra. Su planta noble la ocupaba un corredor -recuerdo del antiguo voladizo 


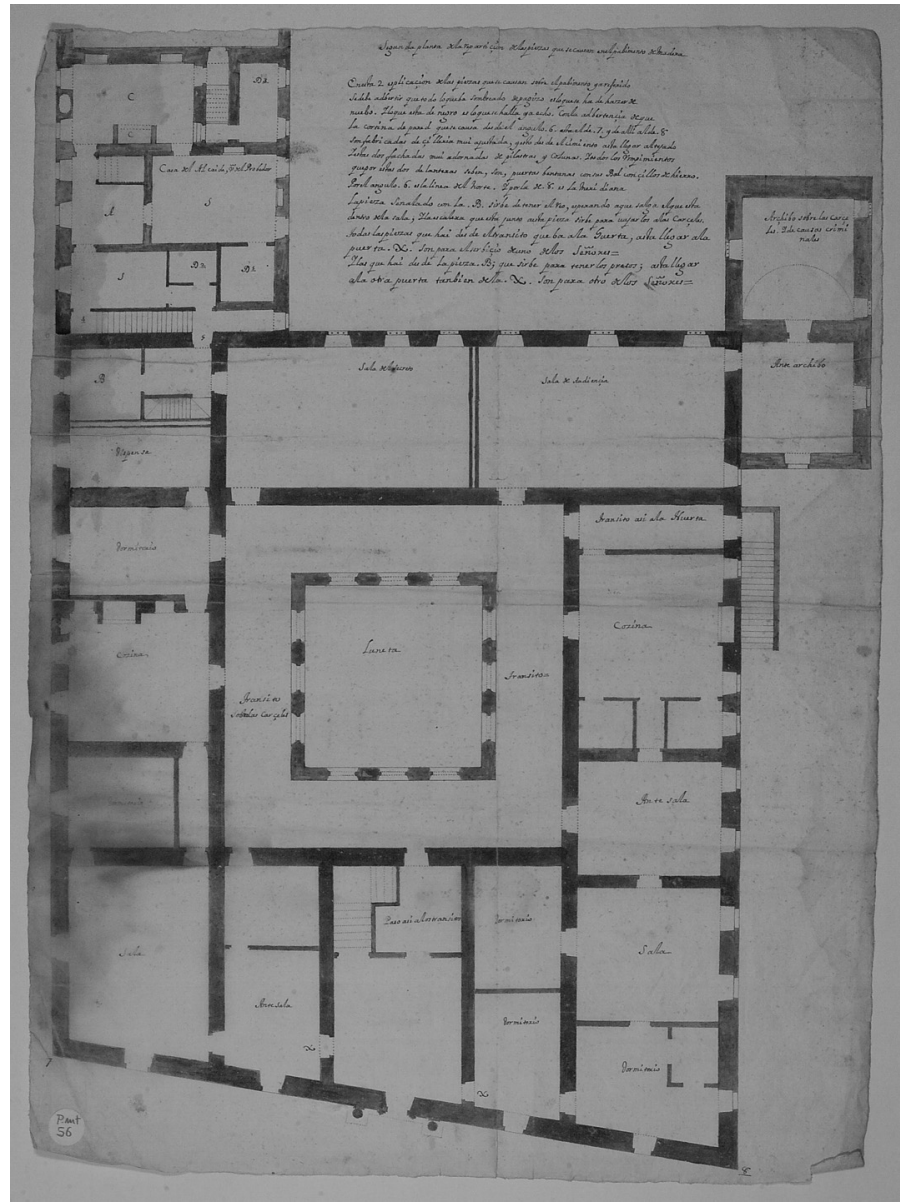

Fig. 8

Anónimo. Proyecto de reforma de la planta alta de la Casa de Calo para palacio de la Inquisición, c. 1727 . AHUS, Planos, ${ }^{\circ} 56$

de madera- que recorría el perímetro de la luneta comunicando las cuatro alas de la casa. Para iluminarlo abrieron en la fachada del patio ventanas con maineles realizadas en piedra. Las cárceles también se distribuyeron por la planta baja de las crujías meridional y oriental, cubiertas siempre con bóvedas. La construcción de los calabozos fue la primera obra acometida ya que modificaba la estructura interna del complejo y era preciso hacerla a fundamentis ${ }^{50}$.

\footnotetext{
${ }^{50}$ Según informó en su testimonio Agustín Marante, al ingresar en la fábrica el 2 de mayo de 1728 se carreteaba piedra de cantería y pizarra y abrían los cimientos para las cárceles. Entre los que
} 


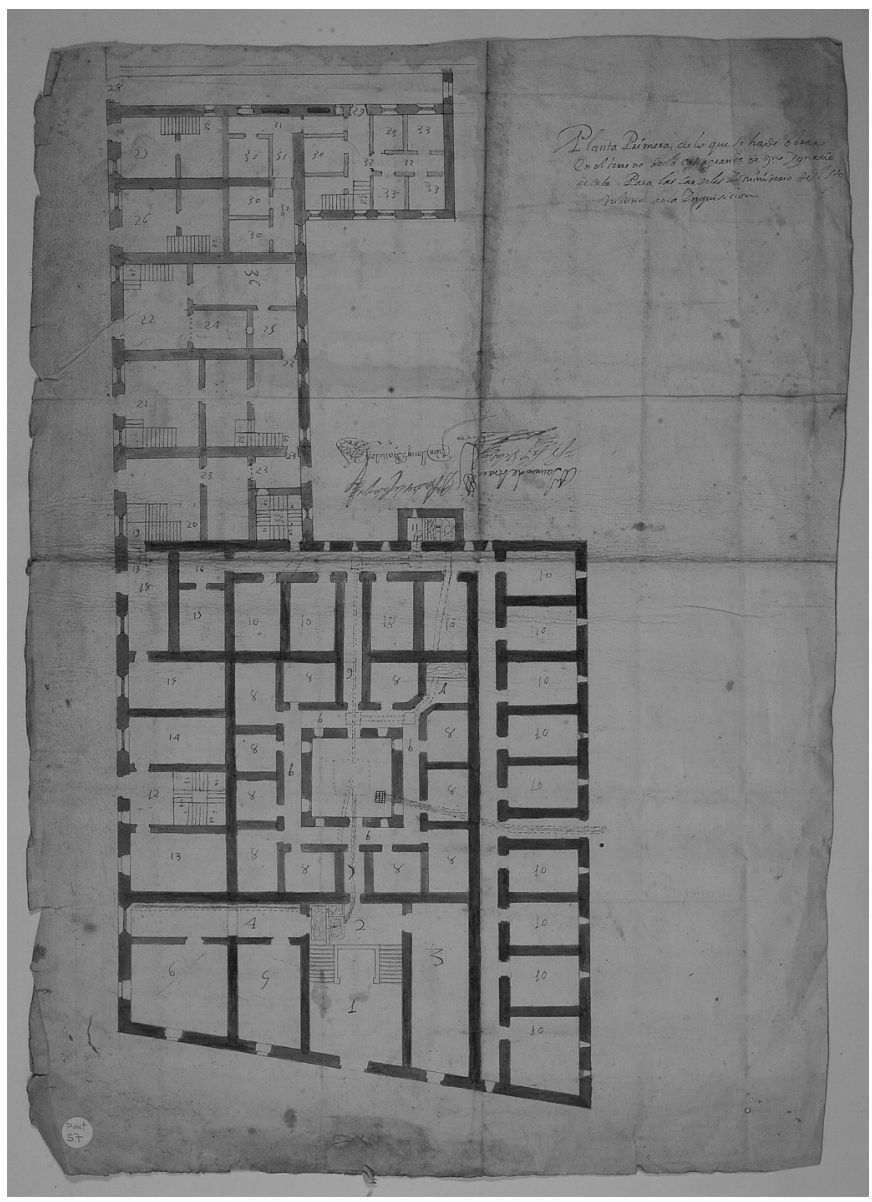

Fig. 9

Anónimo. Proyecto de reforma de la planta baja de la Casa de Calo para palacio de la Inquisición, c. 1727 . AHUS, Planos, $n^{\circ} 57$ anverso

Terminados los espacios destinados a penitenciaría, procedieron a reorganizar la distribución espacial con nuevas divisiones de estancias, entresuelos y escaleras. En las piezas terrenas de las alas septentrional y occidental -las no ocupadas

conocieron los calabozos de este edificio estuvo el colegial de Fonseca Andrés Nicolás Serantes de Andrade, cuyo proceso tuvo lugar en 1776. La censura de las conclusiones de su proceso ha sido publicada en Martín González Fernández, El idioma de la razón. Ilustración e Inquisición en Galicia (1700-1808), Vigo, Nigra Trea, 2008, págs. 709-728, pero este documento no aporta información sobre la distribución y usos del palacio del Tribunal. 


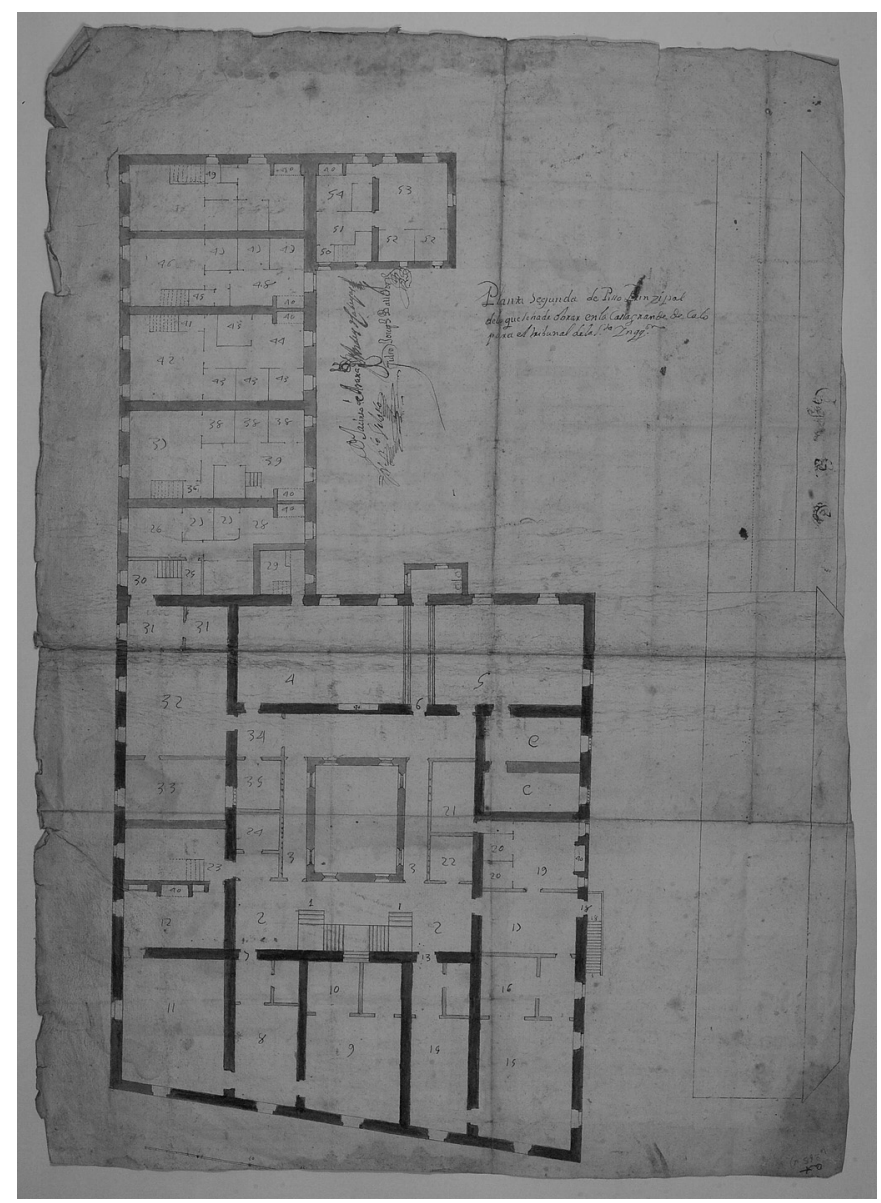

Fig. 10

Anónimo. Proyecto de reforma de la planta baja de la Casa de Calo para palacio de la Inquisición, c. 1727 . AHUS, Planos, $\mathrm{n}^{\circ} 57$ reverso

con los calabozos- se dispusieron los almacenes -granería y bodega- y las caballerizas, además de otras cámaras necesarias para las funciones penitenciarias y administrativas de la Inquisición, como la "sala de tormentos", que estaría próxima a las cárceles. Para comunicar planta baja, entresuelos y planta alta se realizaron varias escaleras entre las que destacó la construida en el zaguán de la entrada occidenta ${ }^{51}$. Se diseñó de dos tiros, toda de cantería, y con una fuente

\footnotetext{
${ }^{51}$ Marante comenta que algunos de los materiales empleados en su fabricación procedían de otras zonas del edificio.
} 
(o pieza para la recogida de agua) en medio, "arrimada contra la pared interior del claustro". El dignificar la entrada al edificio con una escalera noble era uno de los propósitos de los señores inquisidores cuando en 1726 solicitaron proyectos para la reforma del palacio de Monterrey, pues entre los cambios planteados destacaba la reorganización del zaguán y un mejor acceso a la escalera principal.

Los testimonios de los testigos resultan bastante confusos a la hora de establecer qué pasó con la escalera de la crujía norte. En la fachada su puerta central recuperó la función de acceso, por lo que se remodeló su zaguán con la construcción de una nueva escalera: con el primer tramo en piedra, los dos restantes y la barandilla de madera, y una fuente dispuesta junto a su arranque. Por ella se accedía “a las dos havitaciones de los Señores Ynquisidores”. En el ángulo nororiental tendría su correspondiente zaguán una escalera semejante a la descrita, que podía servir para comunicar el palacio de la Inquisición con las casas de los ministros, o las cárceles con las salas de audiencia, tal y como se representa en algunos de los planos que se realizaron antes de la reforma, en concreto los

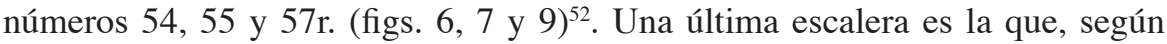
Caniña, servía para bajar a la huerta y que en el plano 57v (fig. 10) se representa en las inmediaciones de la cocina, en la panda meridional ${ }^{53}$. Los zaguanes se pavimentaron en piedra, y para el abastecimiento de las fuentes -que al parecer fueron cuatro, pues se dispuso otra más en la huerta- se realizó una canalización de cantería que tomaba el agua en la arqueta de la Plaza de Mazarelas (hoy denominada de Mazarelos).

Los espacios administrativos y domésticos se concentraron en la planta alta, que quedó para la sala de audiencia, antesalas, oficinas, oratorio y áreas de vivienda para los inquisidores y el servicio. Esto obligó a modificar la compartimentación de las crujías, aunque desconocemos su distribución definitiva. Sabemos por testimonios que se habilitaron entresuelos y se trasladó de lugar la chimenea de la cocina, que permaneció en ala sur, pero ignoramos cómo se articularon las restantes cámaras. Por último, se repararon los pisos de madera -que estaban especialmente dañados en las zonas sin fayado y con menos uso- y la techumbre: haciendo desvanes allí donde no había y una nueva cubierta en teja, semejante a la del resto de la casa, sobre el pasadizo del patio. Además se construyó la gran chimenea que destaca en la crujía norte y que pudo dar

\footnotetext{
${ }^{52}$ Así se disponían en la sede primitiva y así las encontramos también en las casas de Las Palmas y Cartagena.

53 Esta ubicación no parece factible ya que en el plano de la ciudad de Santiago en 1783 se ve claramente como el lateral sur de la casa daba a un callejón y la huerta quedaba al este del conjunto, lo que indica que, de existir, la escalera estaría en la crujía oriental. La única posibilidad de que hubiera estado en la fachada sur es que entre 1732 y 1783 se realizasen cambios en el solar de los inquisidores y éstos cediesen la zona meridional del terreno.
} 
servicio a las estancias de los inquisidores. El inventario de bienes realizado en 1813 a raíz de la primera supresión de la Inquisición española, aún sin referirse a ubicaciones concretas, aporta datos interesantes sobre algunas dependencias del palacio ${ }^{54}$. Entre las que se hallarían en la parte alta encontramos citados el oratorio y su antesala, que debía de cumplir la función de sacristía al ser el lugar donde se disponía la cajonería y se guardaban las cruces procesionales y demás objetos de arte sacro; la Sala del Secreto en la cual los secretarios -cuatro a juzgar por el número de mesas y escribanías citadas- tomaban declaración a los reos; una antesala que separaba la anterior estancia de la Sala de Audiencia; la Secretaría de Secuestros; un cuarto ante la Secretaría de registros; el archivo y la oficina del fiscal ${ }^{55}$.

Pegadas al lienzo norte de Casa, en la "calle que bá al convento de Madres Mercenarias”, erigieron de nueva planta las casas para la vivienda de los Ministros del Santo Oficio (alcaides, proveedor y fiscal). En ellas trabajaron buena parte de los maestros y oficiales que habían participado en las obras previas: el padre Velasco como maestro de obras, Bartolomé Sieiro de aparejador, Julián de la Dehesa y España como sobrestante, y Antonio Lago recordaba también a Francisco Moure, Salvador Rodríguez, Juan Vázquez, Manuel Mareque y Juan Mariño. No nos constan descripciones de estos edificios, ya que quedaban fuera del objeto de disputa entre la familia Calo y el monasterio de San Martín. Sin embargo, por las propuestas de los planos del Archivo Histórico Universitario, podemos estimar que seguirían el modelo galaico de arquitectura doméstica urbana: con zaguán de entrada, despensa, cocina y un par de habitaciones distribuidas entre la planta baja y piso noble. Es posible que la planta y tamaño de las viviendas no fuera siempre idéntico, variando su capacidad y comodidad según la importancia y función de su inquilino dentro del organigrama de la Inquisición.

Del resultado final del complejo quedó constancia en algunos de los planos de la ciudad Compostelana realizados entre 1732 y 1913 -año del derribo de la obra-, entre los que podemos citar el dibujo de 1750 del Instituto de Estudios

\footnotetext{
54 Los primeros estudios acerca de la Inquisición compostelana han corrido a cargo de Barreiro de Váquez Varela que, además de los archivos compostelanos y gallegos, vació los datos del Consejo de la Suprema Inquisición conservados en el archivo de Simancas. Bernardo BARREIRo DE VÁzQUEZ VARELA, "Inventario de los bienes, papeles, alhajas, muebles y otros efectos del suprimido Tribunal de la Inquisición de Galicia”, Galicia Diplomática, t. III, nº 48 (1888), págs. 341-343; t. III n 49 (1888), págs. 345-346 y t. III, nº 50 (1888), págs. 349-351.

55 Entre las escasas noticias que tenemos acerca del edificio se conserva un pliego de gastos del Tribunal de la Inquisición de 1752 en el que se informa de varias reformas y reparaciones como poner el piso de la contaduría y de la oficina de secuestros, hacer una alacena en la segunda casa del tribunal, componer la puerta grande, recomponer el vertedero y la conducción de aguas a la citada casa, reparar las roturas de las cañerías de las fuentes de la Casa Grande, o la limpieza de los desvanes. AHUS, Clero, 1030, s.f.
} 


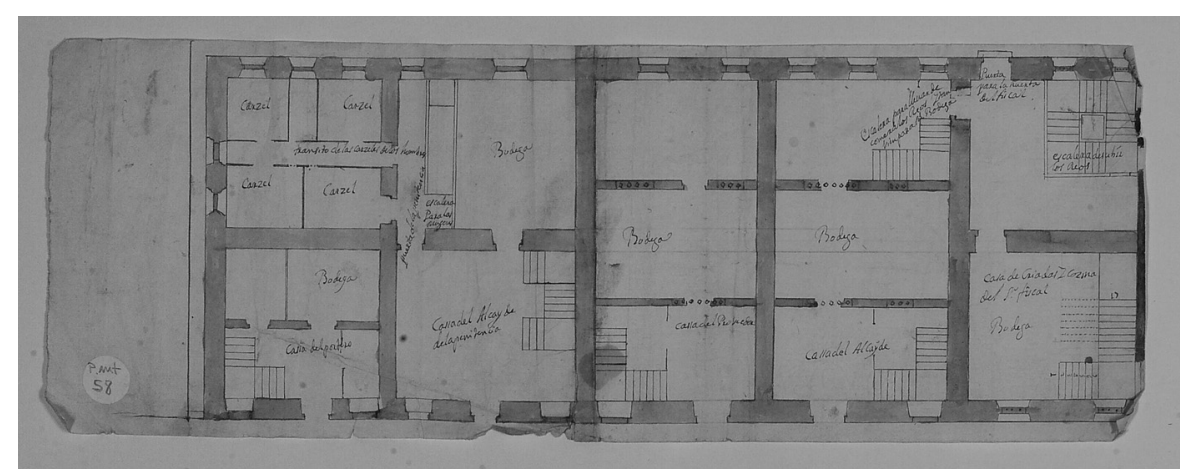

Fig. 11

Anónimo. Proyecto para las casas de los ministros de la Inquisición, c. 1727. AHUS, Planos nº 58

Galegos Padre Sarmiento, el de 1783 que posee el Concello de Santiago (fig. 12), el grabado de Juan López Freire de 1796, el dibujo de la parroquia de Sar, y el dibujo de la muralla de la ciudad con los edificios adosados y las construcciones vecinas, estos dos conservados en el Archivo Histórico Nacional y realizados en el siglo XVIII. En ellos se representa bien el solar o, lo que fue más frecuente, la planta cuadrada del palacio - por lo general con el patio en medio- y en su lado norte su prolongación mediante la hilera de casas. El resto del terreno lo ocupaba la huerta y la extensión del complejo aparece claramente delimitada y separada de los terrenos adyacentes.

\section{LOS PROYECTOS PARA LAS NUEVAS CASAS DE LA InQUiSICIÓN EN COMPOSTELA}

Tras la reconstrucción del palacio de la Inquisición a través de las descripciones de sus artífices podemos afrontar el análisis del grupo de trazas que se realizaron antes de emprender las labores de acondicionamiento, que se conservan en el Archivo Histórico Universitario agrupados con los dibujos de la reforma del primer edificio del Santo Oficio ${ }^{56}$. Consisten en seis planimetrías: tres de ellas presentan distintas propuestas para el piso terreno, dos las obras del piso superior, y la última un plano de las casas de los inquisidores. A pesar de tratarse de dibujos anónimos, es posible distinguir al menos tres autores: el primero habría realizado los planos 54, 56 y la planta de las casas que lleva el número 58 (figs. 6,8 y 11). El tipo de dibujo y la grafía son semejantes para estos tres diseños; sin embargo no se da una correspondencia clara entre los elementos arquitectónicos

\footnotetext{
56 Estos planos han sido recientemente publicados en el catálogo de planos y dibujos de Galicia que forma parte del estudio dirigido por Alfredo Vigo Trasancos (dir.), Galicia ..., Catálogo, págs. 458 y 459.
} 
de ambas plantas, ni tampoco entre las distintas representaciones de las casas que continúan la fachada norte, con lo que podrían ser propuestas dadas en dos momentos diversos. Más clara resulta la paternidad de las dos plantas que ocupan respectivamente anverso y reverso del plano 57 (figs. 9 y 10), y que son las que presentan, entre otras, la firma del Padre Velasco. En el reverso

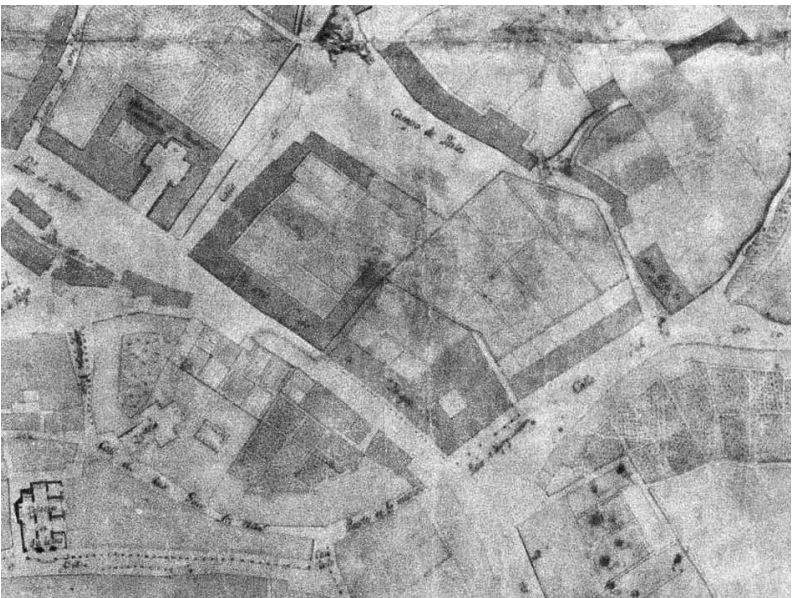

Fig. 12

Detalle del plano de la ciudad de Santiago en 1783 donde se puede ver el palacio de la Inquisición frente a la Porta da Mámoa. Concello de Santiago de Compostela hay además una representación muy esquemática de una de las fachadas del inmueble. El tercer autor fue el encargado de dibujar el plano 55 (fig. 7), otra representación de la planta baja o terrena del complejo. El hecho de que estos planos se conserven junto con una copia de la propuesta de Fernando de Casas para la ampliación de la primera sede, que el propio arquitecto había dado a la comunidad de San Martín Pinario, hizo que Fernández González propusiese como posible origen el archivo de dicho monasterio $^{57}$. Un elemento común en estos diseños es la clara diferenciación entre la primitiva estructura de la «Casa de Calo», por lo general coloreada en tinta negra, y la representación en pajizo de los añadidos. Otros son la transformación del claustro original en luneta; la propuesta de unas nuevas escaleras en el zaguán; y la presencia (como mínimo parcial) de las nuevas casas para los miembros del Santo Oficio, por lo que debieron de haber formado parte del pliego de condiciones de la obra. A partir de aquí varía el modo de resolver la adaptación de ambas plantas a su nueva función, ofreciéndose distintas soluciones a las necesidades de los futuros inquilinos.

El plano 54 (fig. 6) es un proyecto para el piso terreno. En él se dispone una luneta con catorce celdas, y otras cuatro en la crujía oriental, donde también esta-

\footnotetext{
57 Este es el origen, lógico, que Fernández González propone para los planos del proyecto de Fernando de Casas. El archivo de la Inquisición fue incendiado en el siglo XIX y la documentación que sobrevivió la custodia el Archivo Histórico Nacional Madrid. Alberto Fernández GonZález, Fernando de Casas arquitecto..., pág. 183.
} 
ba el cuarto para los desperdicios. Esta panda se une a través de dos puertas con un nuevo cuerpo de dependencias construido en el solar contiguo, hacia el este. Dicha intervención amplía el edificio mediante la creación de un segundo patio de planta rectangular en el que se disponen dos frentes con otras diez celdas, mientras la panda septentrional quedaba para la residencia de los ministros y casa del alcaide. Al quedar libre de cárceles, la crujía sur de la Casa de Calo se destinaba al archivo de causas civiles y, según la leyenda del plano, en su parte alta estaría el de causas criminales. La ubicación de la sala del archivo implicaba una reorganización de los espacios de esta zona, dejando dos cámaras a las que únicamente se podía acceder a través de las escaleras de la huerta, por lo que podía tratarse de piezas para bodegas, función que tenían también las estancias del ala norte. Aquí la antigua escalera desaparece y en su lugar se dispone un almacén. En este diseño -como también sucederá en los siguientes- se percibe al desnivel, bastante pronunciado hacia el Sur, sobre el cual se asentaba el edificio y que fue señalado por Antonio Lago en su declaración. La luneta se encontraba más elevada que el zaguán occidental, de ahí que se abriese a la escalera principal un vano que daba acceso al corredor de celdas y al pequeño patio. Frente a otras propuestas esta implicaba un mayor esfuerzo constructivo y, por tanto, un mayor dispendio económico, motivo por el cual se debió de descartar el proyecto ${ }^{58}$.

Por la caligrafía y el tipo de dibujo parece que el autor del plano 54 fue también responsable de realizar el número 56 (fig. 8) con la planta alta del edificio. Sin embargo, analizando detenidamente este diseño comprobamos que hay una clara falta de correspondencia entre ambos planos, lo que indica que no debieron de formar parte del mismo proyecto. Las disonancias aparecen en las escaleras, el tamaño del cierre del patio, la disposición del archivo, o la distribución de las estancias de las casas adyacentes. Obviamente, el plano 56 formaba parte de un proyecto que contemplaba la traza del piso terreno, pero éste ya no se conserva. Ahora se mantiene la idea original de destinar la planta baja para las cárceles y ubicar ciertas oficinas y áreas residenciales en la planta noble. El aumento de las dimensiones de la luneta, obligaría a sacrificar parte del espacio de las celdas, y respecto al número 54 se varía la disposición del archivo, que se desplaza fuera de la construcción primitiva para construirse a fundamentis en el ángulo suroriental del complejo; de este modo las alas norte y sur quedaban íntegramente para la sala de la audiencia y oficinas de los inquisidores.

El plano 55 (fig. 7) es otra propuesta para el acondicionamiento de la planta baja, pero mejor ajustada que las anteriores a lo descrito por los testigos. Una vez más, los añadidos y transformaciones se distinguen por estar coloreadas en tono

\footnotetext{
${ }^{58}$ En este plano se incluye además un somero dibujo de las casas vecinas de la calle del Hórreo con su huerta que, como se puede comprobar, eran propiedad del monasterio de Pinario.
} 
pajizo, mientras que los muros primitivos permanecen en tinta negra. Al igual que en el plano 54, el antiguo claustro se transforma en luneta al añadirse trece celdas y un espacio para las inmundicias. Ahora, en lugar de adosar un segundo patio para las cárceles, se emplean para ello las crujías oriental y meridional, y se señala siempre la presencia de techos de bóveda de arista o de cañón. En el zaguán de la entrada principal se sigue disponiendo la gran escalera, y en la entrada norte la correspondiente a la puerta lateral del edificio; pero ninguna de ellas con las fuentes que citan los testigos. En la panda septentrional se dispondrían los almacenes, mientras que en el ángulo nororiental habría otra escalera que servía de acceso a la sala de los reos de la primera planta, donde estarían las restantes salas. Como curiosidad apuntar que el autor fue el único que no consideró necesario dibujar los vanos de las fachadas principales del edificio, pero que optó por señalar el espacio de la lonja que corría frente a buena parte de la fachada occidental.

A nuestro parecer los proyectos que más se aproximan al resultado final de las nuevas casas de la Inquisición son los representados en el plano 57 (figs. 9 y 10): en el anverso el piso terreno y en el reverso la planta superior. Al contrario que las propuestas anteriores, donde la estructura precedente era claramente diferenciable respecto a las modificaciones y añadidos, en estos dibujos lo añadido no se representa en pajizo, prefiriéndose una combinación de grises que en algún detalle resulta engañosa, pero que es posible desentrañar gracias a las otras trazas y a los testimonios de quienes trabajaron en su construcción. Las leyendas -que debían estar en folio aparte-, se han perdido, por lo que no siempre es fácil determinar cuál era la función pensada para cada espacio.

La planta baja (fig. 9) se asemeja en lo fundamental al diseño del plano 55: con una escalera de doble tiro en el zaguán a partir de la cual se accede al antiguo patio, donde se han dispuesto diez celdas - marcadas con el número 8- y un cuarto para los desperdicios, todas dispuestas alrededor de la luneta y comunicados por un corredor que recorre el perímetro del patio. Las pandas oriental y meridional albergan doce cárceles -éstas con el número 10-, pero ahora las de la crujía sur se adosan en batería al muro de cierre, lo cual llevó a abrir pequeños vanos para su iluminación tal y como describieron los testigos. En este lienzo se abre una puerta hacia la huerta que podía corresponderse con la que tenía originariamente el edificio. En el entorno del zaguán occidental se dispusieron unas salas que servirían para oficinas y almacenes, incluyéndose como novedad un corredor que comunicaba con el rellano de la escalera, donde se representa la arqueta de la fuente. La representación de las canalizaciones de agua y de las fuentes del edificio es una de las novedades de este diseño respecto a los anteriores. Además de la fuente de la escalera principal vemos que en el cuarto de las inmundicias también había una arqueta, y otra más en una pieza que se adosó al 
muro este. La luneta, por su parte, contaba con un registro para la evacuación de las aguas que eran conducidas hacia la huerta. Donde no se representa ninguna fuente es junto a la escalera de la panda norte, muy semejante a la representada en el plano 55. Esta crujía debió de destinarse a zona de almacenes, tal y como sugiere la disposición de sus estancias, a las que se accedía a través de las dos puertas que había en su fachada. En la pieza nororiental se dispone una tercera escalera pensada para comunicar el edificio con una de las viviendas para los ministros y tras ella -ya en la crujía oriental-, se abren dos habitaciones (a modo de antesala y sala) que por su proximidad a las cárceles pudieron idearse como cámara y antecámara del tormento. Las viviendas que se realizaron para los miembros del Santo Oficio se dispusieron en L y se plantearon según la tipología propia de las casas compostelanas: de dos alturas, con un acceso amplio con escaleras al piso superior, y dos o tres habitaciones por planta. Las tres primeras están comunicadas entre sí y las dos últimas presentan un tamaño considerablemente menor, siendo más estrechas y con sólo dos pequeñas habitaciones en la planta baja, que se compensan al ganar espacio en el piso superior. Hay una sexta a la cual se accede a través de un callejón; esta casa es amplia en el piso terreno, con varias estancias distribuidas en ángulo, pero reduce su espacio en el piso alto, equiparándose grosso modo su tamaño a las anteriores.

La planta alta de la casa (fig. 10) acogía las salas de audiencia -dispuestas en la crujía oriental-, archivo, zonas comunes y dos viviendas, cada una con su cocina y áreas de servicio: una en la panda norte y la otra en la sur. Se conserva el espacio central acomodado a la luneta y con ventanas abiertas hacia este patio. La escalera de la panda norte llega hasta la segunda planta pero, según el diseño, para acceder a ella desde la zona de las cárceles había que salir del edificio y entrar por la puerta lateral, lo cual complicaba los tránsitos y la funcionalidad del inmueble. Además de la citada, en el frente occidental se dispone una escalera de doble rampa articulada en dos tramos acodados que comunicaba la habitación sobre el zaguán con el corredor del claustro. Parece que, sufriendo variaciones una vez iniciadas las obras, el presente proyecto fue el que finalmente salió adelante, siendo el único que además de llevar la firma de Velasco -bien como autor, bien como representante de San Martín Pinario- presenta las de los representantes de la Inquisición: Jacinto de Arana, Andrés de Cabrejas e Isidro José Vallejos.

Por último, el plano 58 (fig. 11) presenta otro diseño para las casas de los alcaides, provisor y fiscal, aunque es muy semejante a los anteriores: de dos plantas; con un par de piezas en la planta baja, acceso al piso superior; algunas de ellas comunicadas entre sí, y la más próxima al edificio de la Inquisición con comunicación con este inmueble. En este caso vemos que, además, se disponen unas celdas en la última casa. Es posible que los planos de estas casas sufriesen variaciones, teniendo clara la idea principal en su distribución y tamaños pero 
siendo flexibles a la hora de distribuir los interiores hasta el momento de elegir el diseño definitivo, que ignoramos cuál pudo ser ya que es poca la información que tenemos de ellas.

\section{PRopuesta DE AUTORÍA}

En la obra Galicia artística Couselo Bouzas apuntó a Fernando de Casas y Novoa como posible autor de las casas de la Inquisición en Porta da Mámoa. Era, según sus palabras, una de las pocas obras civiles abordadas por dicho arquitecto $^{59}$. Como ya hemos comentado, el maestro de obras catedralicio dio un proyecto para remodelar el Palacio de Monterrey; pero éste quedó irrealizado debido al traslado del Tribunal a la «Casa de Calo». Finalizan aquí las noticias que vinculan a Casas y Novoa con la Inquisición; la falta de datos documentales que constaten su implicación, o el hecho de que no aparezca citado en la abundante documentación que resultó de los trabajos de las nuevas casas del Santo Oficio, parecen señalar que el arquitecto no estuvo relacionado con estos trabajos, pero tampoco nos permiten descartarlo del todo. Podría haberse repetido la colaboración entre Casas y fray Francisco Velasco, que venían de trabajar juntos en el acueducto coruñés de San Pedro de Visma. La participación del monje benedictino al frente de las obras fue señalada por todos los testigos, y su implicación desde el momento de la resolución del pleito entre Pinario y la Inquisición ha quedado probada por las actas capitulares del monasterio. Pero ¿podría haber sido Velasco el maestro encargado de dar también las trazas para la reforma? Sin duda su elección abarataría el coste del proyecto, y contaba con capacidad suficiente como para diseñar la remodelación. Además, su firma consta en el plano 57 del Archivo Histórico Universitario junto con la de los inquisidores, siendo la única de un integrante de la comunidad benedictina. Cierto es que podría haber firmado como miembro del Capítulo, pero si hubiera sido necesario el acuerdo entre ambas instituciones, además de su firma como maestro de obras y capitular debería constar también la del abad. Esto nos lleva a tenerlo en consideración como posible autor del palacio de la Inquisición. Aunque su perfil profesional está más próximo al de un maestro de obras de calidad que al de un tracista, el tipo de intervención que requería la Casa de Calo pudo haberlo desempeñado un hombre como Velasco, que tenía en su haber la reparación y consolidación de la Catedral de Tui, la remodelación de la iglesia de As Encrobas, la dirección y posible diseño de la gran crujía de celdas de San Martín Pinario y que, no lo olvidemos, había obtenido el puesto de Maestro de Obras del Rey en Galicia en 1727.

\footnotetext{
59 José Couselo BouZAS, Galicia artística en el siglo XVIII y primer tercio del XIX, Santiago de Compostela, Instituto de Estudios Gallegos "Padre Sarmiento”, 2004, pág. 241.
} 
La reforma de la penitenciaría y área de oficinas del Palacio de Monterrey acabó siendo para los inquisidores la oportunidad de hacerse con una sede más moderna y mucho mejor adaptada a sus concretas necesidades. La resolución amistosa del pleito mantenido con los benedictinos en 1727 solventó los problemas derivados de un inmueble pensado exclusivamente para una función doméstica, al tiempo que los regulares conseguían deshacerse de unos vecinos indeseados.

La adquisición y posterior asentamiento de la Inquisición en la Casa de Calo, situada frente a la Porta da Mámoa, se llevó a cabo según el ritual de instalación perpetrado por el Santo Oficio: localizar el edificio o edificios destinados a convertirse en su sede y acomodarlos a su nueva función conservando su estructura fundamental. Una vez más, los inquisidores renunciaron a construir un edificio de nueva planta. El inmueble que encontraron ofrecía numerosas ventajas respecto al Palacio de Monterrey y a otros tribunales españoles. Comparando los solares parece que perdieron metros cuadrados, pero la estructura claustral de la Casa de Calo les beneficiaba a la hora de organizar las distintas áreas del tribunal, que debía mantener la tipología propia de las casas de la Inquisición: con una zona para la penitenciaria, otra para los servicios judiciales y administrativos y una última para vivienda de los inquisidores y principales funcionarios. Además, el amplio espacio de huerta les permitió disponer parte de la arquitectura doméstica en el mismo recinto, pero si interferir en el área del tribunal. El resultado fue un establecimiento mucho más funcional, ajustado a sus necesidades y, por consiguiente, cómodo; y ello sin descuidar la proyección de una imagen representativa del poder de la institución a través de sus frentes principales, algo que ya se planteaba en la reforma pensada para el Palacio de Monterrey. Lo excepcional de esta intervención reside en que, mientras lo habitual era que la instalación de los inquisidores se hiciera efectiva tras una primera reforma esencial -por lo general centrada en la construcción de las cárceles- y la adaptación del complejo a sus necesidades se diera en reformas progresivas y espaciadas en el tiempo, en este caso se optó por llevar a cabo una intervención integral, de manera que una vez instalados solo fueron necesarias las habituales labores de mantenimiento.

La directa implicación de los benedictinos en la obra también debe ser destacada. No sólo por haber sido ellos los que propiciaron el traslado y llevaron a cabo los trámites necesarios para la adquisición del inmueble, sino por haber puesto a sus principales maestros al frente de los trabajos y quien sabe si de toda 
la obra. A la tradicional atribución del proyecto a Fernando de Casas hemos de sumar la posibilidad de que en realidad perteneciera a fray Francisco Velasco, pues sabemos que se hizo cargo de materializar la compra y de dirigir los trabajos como maestro de obras.

Asimismo es preciso resaltar la riqueza y la importancia de documentación que hemos empleado a la hora de llevar a cabo este estudio: las noticias aportadas por las actas de San Martín Pinario, la valiosas descripciones del pleito entre los descendientes de Ignacio de la Vega y Calo y los benedictinos, y el conjunto de planos con los proyectos de reforma de la sede primitiva y de la «Casa de Calo», que nos han permitido conocer el contexto en el cual se produce el traslado de la sede y reconstruir hipotéticamente la casas de la Inquisición en la Porta da Mámoa, tanto antes como después de la reforma. Con todo, quedan lagunas que únicamente se podrán cubrir con la aparición de nuevos documentos. El hecho de que ninguna de las trazas conservadas responda a las descripciones dadas por los maestros que trabajaron en la reforma del edificio o de aquellos que lo conocieron funcionando ya como sede de la Inquisición indica que, o bien entre ellos no se encuentra el proyecto elegido, o éste no se ejecutó según lo dibujado. Todavía quedan dudas sobre la distribución de las estancias del piso alto, la planta de escalera principal, el planteamiento de los tránsitos del edificio, o cual fue el diseño definitivo de las casas de los ministros. Detalles menores de una remodelación que supuso la transformación de una tradicional vivienda con patio compostelana en un palacio de la Inquisición.

\section{BIBLIOGRAFÍA}

Anaya Hernández, Luis Alberto, Alemán Hernández, Rosario, "Las casas de la Inquisición de las Palmas y algunas características del tribunal canario", IV Coloquio de historia canario-americana, vol. 2, 1982, págs. 489-512.

Ballesteros Gaibrois, Manuel, "Nuevos datos para la historia del edificio de la Inquisición en Cartagena", Homenaje a D. Agustín Millán Carlo, Vol. 2, 1975, págs. 325-342.

Barreiro de Vázquez Varela, Bernardo, "Las casas primitivas del Santo Oficio en Santiago", Galicia diplomática. Tomo I, $\mathrm{n}^{\circ} 35$ (1883), págs. 249-253, Tomo III, $\mathrm{n}^{\circ} 48$ (1888), págs. 341-343; no 49 (1888), págs. 345-346 y n 50 (1888), págs. 349-351.

Blasco Esquivias, Beatriz (dir.), La casa. Evolución del espacio doméstico en España, Vol. 1, Ediciones El Viso, Madrid, 2006.

Contreras, Jaime, El Santo Oficio de la Inquisición de Galicia 1560-1700. Poder, sociedad y cultura, Madrid, Akal, 1982.

Couselo Bouzas, José, Galicia artística en el siglo XVIII y primer tercio del XIX, Santiago de Compostela, Instituto de Estudios Gallegos "Padre Sarmiento", 2004. 
Bonet Correa, Antonio, La arquitectura en Galicia durante el siglo XVII, Madrid, CSIC, 1984 ( $2^{\mathrm{a}}$ ed.).

Costa Buján, Pablo, Santiago de Compostela 1850-1960. Desenvolvemento urbano outra arquitectura, Santiago de Compostela, COAG, 1989.

Diez Cuevas, Luis Carlos, El palacio de la Inquisición de Madrid, Madrid, Imaginógrafo, 1998.

Fernández Álvarez, María Agustina, Arte y sociedad en Compostela, 1660-1710, Sada, Edicións do Castro, 1996.

Fernández González, Alberto, Fernando de Casas arquitecto en Compostela, Vigo, Consorcio de Santiago; Nigra Trea, 2008.

García Iglesias, José Manuel (dir.), Compostela e o Colexio de San Clemente de Pasantes. Santiago de Compostela, Xunta de Galicia, 2004.

González Fernández, Martín, El idioma de la razón. Ilustración e Inquisición en Galicia (1700-1808), Vigo, Nigra Trea, 2008.

González García-Paz, Sebastián, O Colexio de San Clemente de Pasantes de Compostela. Santiago de Compostela, Consorcio de Santiago, Universidade de Santiago, 1993.

Ortega Romero, María del Socorro, "Un proyecto de Fernando de Casas para el tribunal de la Inquisición de Santiago", en Jubilatio. Homenaje de la Facultad de Geografía e Historia a los profesores don Manuel Lucas Álvarez y don Ángel Rodríguez González, vol. II, Santiago de Compostela, Universidad de Santiago de Compostela, págs. 653-668.

Pérez, Joseph, Breve historia de la Inquisición en España, Madrid, Crítica, 2009.

Rosende Valdés, Andrés, "La imagen urbana de Compostela en tiempos de Carlos V", en Eiras Roel, Antonio (coord.), El reino de Galicia en la época del emperador Carlos V, Xunta de Galicia, Consellería de Cultura Comunicación Social e Turismo, Dirección Xeral de Patrimonio Cultural, Santiago de Compostela, 2000, págs. 637-669.

Rosende Valdés, Andrés, Unha historia urbana, Compostela 1595-1780, Vigo, Nigra Trea, 2004.

Taín Guzmán, Miguel, Domingo de Andrade, maestro de obras de la catedral de Santiago (1639-1712), Sada, Edicións do Castro, 1998.

Taín Guzmán, Miguel, "El urbanismo de Santiago de Compostela: un plano con las plazuelas de San Martín y San Miguel, de 1709”, Espacio, Tiempo y Forma, Vol. 11, 1998, págs. 199-215.

Taín Guzmán, Miguel, La Casa del Cabildo de Santiago de Compostela (1754-1759): "pro commoditate ac ornato urbis", Madrid, Electa, Consorcio de Santiago, 2000.

Vázquez Astorga, Mónica, "Santiago de Compostela: lenguajes arquitectónicos y su reinterpretación en los primeros treinta años del siglo XX", Anuario Brigantino, n 32 (2009), págs. 351-366.

Vila Jato, María Dolores, "El Monasterio. La Edad Moderna", Santiago. San Martín Pinario, Santiago, Xunta de Galicia, 1999.

Vigo Transancos, Alfredo (dir.), Galicia y el siglo XVIII. Planos y dibujos de arquitectura y urbanismo (1701-1800). Catálogo de planos y dibujos, A Coruña, Fundación Barrié, 2012. 